\title{
Xwnt-5A: a maternal Wnt that affects morphogenetic movements after overexpression in embryos of Xenopus laevis
}

\author{
Randall T. Moon ${ }^{1, \star}$, Robert M. Campbell ${ }^{1}$, Jan L. Christian ${ }^{1, \dagger, \neq}$, L. Lynn McGrew ${ }^{1, \neq}$, John Shih ${ }^{2, \ddagger}$ and \\ Scott Fraser ${ }^{2}$ \\ 1Department of Pharmacology, University of Washington School of Medicine, Seattle, WA 98195, USA \\ ${ }^{2}$ Beckman Institute, California Institute of Technology, Pasadena, CA 91125, USA \\ *Author for correspondence \\ tPresent address: Department of Cell Biology and Anatomy, Oregon Health Sciences University, Portland, Oregon 97201, USA \\ ¥Contributed equally to the project
}

\section{SUMMARY}

To contribute to an understanding of the roles and mechanisms of action of Wnts in early vertebrate development, we have characterized the normal expression of Xenopus laevis Wnt-5A, and investigated the consequences of misexpression of this putative signalling factor. Xwnt-5A transcripts are expressed throughout development, and are enriched in both the anterior and posterior regions of embryos at late stages of development, where they are found primarily in ectoderm, with lower levels of expression in mesoderm. Overexpression of Xwnt-5A in Xenopus embryos leads to complex malformations distinct from those achieved by ectopic expression of Xwnts $-1,-3 \mathrm{~A}$, or $\mathbf{- 8}$. This phenotype is unlikely to result from $X w n t-5 A$ acting as an inducing agent, as overexpression of Xwnt-5A does not rescue dorsal structures in UV-irradiated embryos, does not

\section{INTRODUCTION}

There is considerable interest in the molecules and mechanisms that underlie pattern formation, and the discovery that Wnt-1 (int-1) is the vertebrate ortholog of the Drosophila segment polarity gene wingless (Rijsewijk et al., 1987) led to speculation that Wnt-1 is involved in pattern formation in vertebrates. Any hypotheses on the involvement of Wnts in pattern formation need to accomodate the fact that $W n t-1$ is a secreted protein, which interacts with the plasma membrane (Papkoff and Schryver, 1990) and extracellular matrix (Bradley and Brown, 1990) of secreting and adjacent cells. Wnts may act in an autocrine or paracrine fashion through a receptor-mediated pathway to influence intercellular communication (van den Heuvel et al., 1989; Olson et al., 1991; Jue et al., 1992), though neither the receptors for Wnt-1 nor the signal transduction pathways activated by Wnt-1 are currently known. The recent cloning of additional members of the Wnt gene family from mouse (reviewed by Nusse and Varmus, 1992; McMahon, 1992) and Xenopus (reviewed by Moon, 1993), and the demonstration that these Wnts are expressed in both neural and non-neural tissues, induce mesoderm in blastula caps, and $X w n t-5 \mathrm{~A}$ does not alter the endogenous patterns of expression of goosecoid, Xbra, or Xwnt-8. To pursue whether Xwnt-5A has the capacity to affect morphogenetic movements, we investigated whether overexpression of $X w n t-5 \mathrm{~A}$ alters the normal elongation of blastula cap explants induced by activin. Intriguingly, Xwnt-5A blocks the elongation of blastula caps in response to activin, without blocking the differentiation of either dorsal or ventral mesoderm within these explants. The data are consistent with $X w n t$ 5A having the potential activity of modifying the morphogenetic movements of tissues.

Key words: Xenopus, Wnt, embryonic development, pattern formation, growth factors, morphogenesis raises the possibility that diverse processes in vertebrate development are influenced by the local expression of specific Wnts.

The activities and likely functions of specific Wnts are best understood for Drosophila and murine Wnt-1 (reviewed by McMahon, 1992; Nusse and Varmus, 1992), and a Xenopus Wnt (Xwnt), Xwnt-8 (Christian and Moon, 1993a,b). Direct evidence that Wnt-1 participates in the formation of the vertebrate nervous system has been provided by disruption of the Wnt-1 gene in mice by homologous recombination, leading to embryos deficient in specific regions of the brain (McMahon and Bradley, 1990; Thomas and Capecchi, 1990). Supporting the idea that Wnts are involved in processes outside of the nervous system, there is now strong evidence that endogenous Xwnt-8 functions downstream of mesoderm inducing growth factors to promote formation of ventral mesoderm, and to alter cellular responses to dorsalizing signals from the gastrula organizer (Christian and Moon, 1993a,b). Prior to the expression of endogenous Xwnt-8, a maternal Xwnt or noggin activity may operate in the Nieuwkoop center, by synergizing with mesoderm inducing growth factors to 
promote the localized formation of dorsal mesoderm, and hence the gastrula organizer (reviewed by Moon and Christian, 1992; Christian and Moon, 1993a; Sive, 1993).

$W n t-5 \mathrm{~A}$ is a Wnt-1-related gene identified in mouse (Gavin et al., 1990), Xenopus (Christian et al., 1991a), and zebrafish (Krauss et al., 1992). Its sequence and pattern of expression have been best characterized in mouse (Gavin et al., 1990), where it is expressed throughout development. Elevated expression of Wnt-5A is correlated with posterior position rather than with specific cell lineage in embryos younger than 9.5 days, though transcripts are also found throughout the embryo. In older embryos, Wnt-5A expression is elevated in regions of the face, and in a graded manner in developing limb buds (Gavin et al., 1990). In Xenopus, Xwnt-5A is expressed as a maternal transcript, which persists through development (Christian et al., 1991a). In the present study we have initiated our investigation of the potential functions of Xwnt-5A in Xenopus embryos, as well as the potential cellular responses to Xwnt$5 \mathrm{~A}$ signals, by examining the spatial pattern of $X w n t-5 \mathrm{~A}$, and the consequences of overexpression of this Xwnt.

\section{MATERIALS AND METHODS}

\section{cDNA isolation and sequencing of $X w n t-5 A$}

A cDNA partially encoding Xwnt-5A (Christian et al., 1991a) was used to screen (Maniatis et al., 1982) $1.2 \times 10^{6}$ independent bacteriophage from a Xenopus oocyte cDNA library in $\lambda$ gtl0 (Rebagliati et al., 1985). Three bacteriophage rescreened positive, though two later proved to be identical cDNAs. Bacteriophage DNA was isolated from the unique clones $\lambda \mathrm{G} 5$ and $\lambda \mathrm{G} 6$, and the cDNA inserts were isolated from low melting point agarose and ligated into pGem 2 (Promega). Restriction fragments of these cDNAs were subcloned into pGem 4 and fully sequenced on both strands using the dideoxy chain termination method (Sanger et al., 1977), employing SP6 and T7 promoter primers (Promega), as well as unique primers (17 nt). The composite DNA sequence was analyzed with a DNA Inspector IIe program (Textco).

\section{In vitro transcription and microinjection}

To prepare the construct G6EcoR1/SP64T, an EcoR1 insert from the $\lambda \mathrm{G} 6$ clone (approximately $2 \mathrm{~kb}$ ) was blunted with Klenow fragment, cloned into the unique BgIII site of SP64T (Krieg and Melton, 1984), and transformed into E. coli strain DH5 . The construct was linearized with $\mathrm{XbaI}$, followed by in vitro transcription in the presence of cap analogue (Moon and Christian, 1989). The integrity and size of all transcribed RNA was verified by separation on formaldehyde agarose gels. The ability of the RNA to be translated to yield a polypeptide of the predicted size was established by in vitro translation in a rabbit reticulocyte lysate and separation of the translation products on SDS polyacrylamide gels. The coding region of Xwnt-5A was also cloned into a vector under the control of a cytoskeletal actin promoter, as described by Christian and Moon (1993b).

Synthetic RNAs or DNAs were microinjected into fertilized Xenopus eggs, or into blastomeres of the developing embryo (see text), as previously described (Moon and Christian, 1989). In some experiments beta-galactosidase RNA was transcribed from a plasmid (a gift of R. Harland) and mixed with the Xwnt-5A RNA. In other experiments, fertilized eggs were UV-irradiated early in the first cell cycle (Christian et al., 1991), prior to microinjection of Xwnt-5A RNA. Following injection, RNA was extracted from 5-10 embryos at selected times (Moon and Christian, 1989), and separated on formaldehyde agarose gels next to standard curves of synthetic Xwnt-5A RNA. The gels were blotted to nitrocellulose and probed with ${ }^{32} \mathrm{P}$-labeled random primed (Feinberg and Vogelstein, 1984) Xwnt-5A DNA probes.

\section{Isolation and culture of blastula caps in the presence or absence of activin}

To assess the effects of Xwnt-5A on the differentiation of isolated blastula caps, the animal poles of both blastomeres of two cell embryos were injected with 25-75 pg Xwnt-5A RNA, and blastula caps corresponding to approximately the upper one quarter to one fifth of stage 7-8 blastula were obtained (Christian et al., 1992). Blastula caps were cultured in the presence or absence of $10 \mathrm{ng} / \mathrm{ml}$ recombinant human activin A (a gift of Genentech) until control embryos reached stage 40. Explants were then fixed, embedded, sectioned (Christian et al., 1992, Christian and Moon, 1993b) and scored morphologically for various mesodermal cell types (Green et al., 1990).

\section{Histology and whole-mount immunocytochemistry}

To assess developmental defects attributable to overexpression of Xwnt-5A, embryos were fixed, embedded in paraffin, sectioned, and stained (Kelly et al., 1991). Embryos were also processed for whole-mount immunocytochemistry (Klymkowsky and Hanken, 1991), employing the neural specific monoclonal antibody 2G9 (Jones and Woodland, 1989), the muscle-specific monoclonal antibody 12/101 (Kintner and Brockes, 1984), or commercial (BioRad) antibodies to beta-galactosidase.

\section{Embryo microdissection and RNase protection assay}

At selected stages (see text), RNA was isolated from embryos and digested with DNase I (Moon and Christian, 1989). At stage 40, embryos were microdissected into four regions: the head, tail, middorsal region, and mid-ventral region, then RNA was isolated as above.

For RNase protection assays, the PCR-derived Xwnt-5A clone described previously (Christian et al., 1991a) was linearized with Bam $\mathrm{H} 1,{ }^{32} \mathrm{P}-$ labeled antisense RNA was transcribed in vitro with SP6 RNA polymerase then samples were processed for RNase protection using standard protocols (Ausubel et al., 1988). As a control, equivalent proportions of RNA were electrophoresed on $1.3 \%$ agarose-formaldehyde gels, blotted to nitrocellulose, and probed with a ${ }^{32} \mathrm{P}-$ labeled EF1 $\alpha$ probe.

To quantify the levels of Xwnt-5A in development, $100 \mu \mathrm{g}$ of total RNA from each developmental stage was processed in the RNase protection assay. Synthetic target Xwnt-5A RNA was mixed with carrier tRNA and used to generate a standard curve, with tRNA as a negative control. Protected bands on the autoradiogram were scanned with an Isco densitometer, and the relative peak areas were determined by weight. The level of endogenous Xwnt-5A transcripts was in part calculated on the assumption of approximately $5 \mu \mathrm{g}$ of total RNA for early embryos (Gurdon and Wickens, 1983).

\section{Whole-mount in situ hybridization}

Digoxigenin-labeled sense and antisense probes for Xwnt-5A RNA, Xwnt-8 (Christian and Moon, 1993b), goosecoid (Christian and Moon, 1993b), and Xbra (Smith et al., 1991) were size-reduced and hybridized to fixed embryos (Harland, 1991). Following photography of the whole mounts, embryos were embedded, sectioned and photographed (Kelly et al., 1991).

\section{RESULTS}

\section{Sequence analysis of Xwnt-5A}

The predicted amino acid sequence of $X w n t-5 \mathrm{~A}$ is shown in 
$144-1$

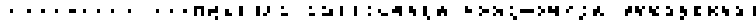

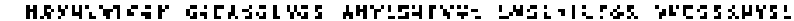

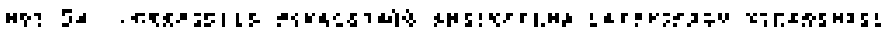

$$
\text { r tr } 2+4,4
$$

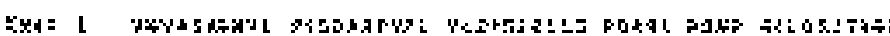

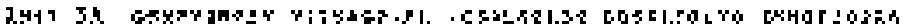

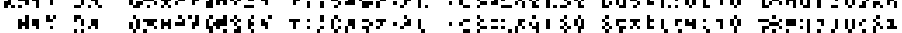

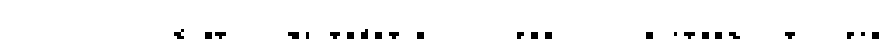

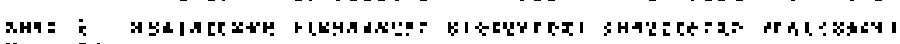

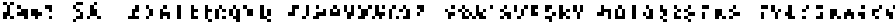

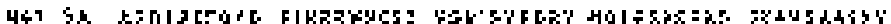

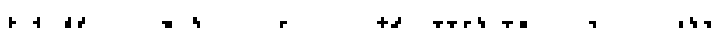

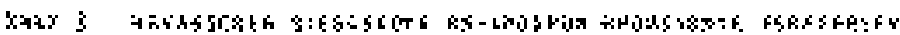

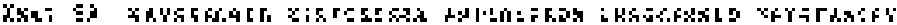

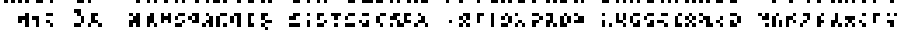

- 1.

center

arariar

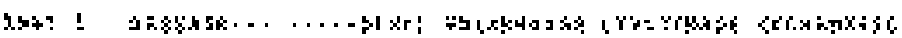

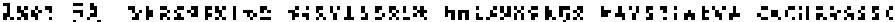

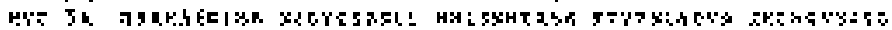

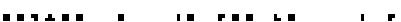

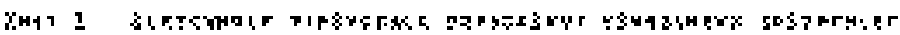

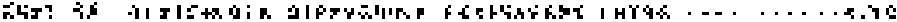

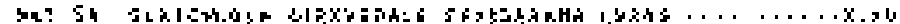

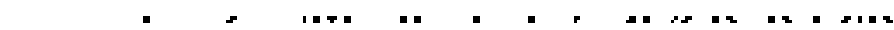

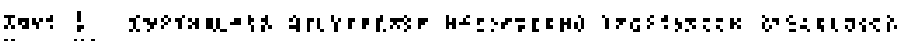

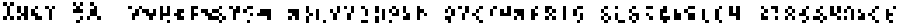

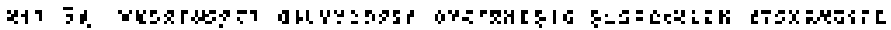

F t r hdr

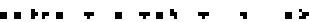

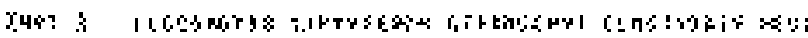

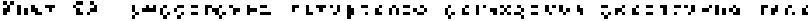

We

Fig. 1. Comparison of the predicted amino acid sequences of Xwnt-5A (Genbank accession number L19716), murine Wnt-5A (Gavin et al., 1990), and Xwnt-1 (Noordermeer et al., 1989). Identical residues are marked by asterisks, and gaps indicated by dashes were introduced to yield the highest degree of identity.
Fig. 1, aligned with the amino acid sequences of Xenopus Wnt-1 (int-1; Nordermeer et al., 1989) and murine Wnt-5A (Gavin et al., 1990). Sequencing of $260 \mathrm{nt} 5^{\prime}$ of the putative start site did not establish an alternative open reading frame (data not shown). Xwnt-5A has $85 \%$ amino acid identity with Wnt-5A, only $42 \%$ identity with Xwnt-1 (Fig. 1), and similarly low identity to other murine Wnts (data not shown). Significantly, the positions of 23 of 24 cysteine residues are absolutely conserved between Xwnt-5A and Wnt-5A (Fig. 1), with the sole exception at position 36. This high degree of conservation of the positions of cysteines is diagnostic for members of the Wnt family (Gavin et al., 1990; Christian et al., 1991a). The predicted hydrophobic leader sequence preceding the two tryptophans at positions 47-48 are not conserved between Xwnt-5A and Wnt-5A, although both are equivalently hydrophobic (data not shown). Four potential glycosylation sites are completely conserved between $X w n t-5 \mathrm{~A}$ and $W n t-5 \mathrm{~A}$ (NCS, NTS, NES, and NKT, starting at amino acid positions 117, 123, 326, and 340, respectively, in Fig. 1).

\section{Expression of Xwnt-5A transcripts during early development}

Having established that the cDNAs did indeed encode the Xenopus ortholog of murine Wnt-5A, we first used RNase protection assays to quantify the level of endogenous Xwnt$5 \mathrm{~A}$ transcripts during early development. RNase protection assays revealed that $X w n t-5 \mathrm{~A}$ transcripts are detectable in oocytes, and in all stages of developing embryos (Table 1), consistent with RNA blot analysis (Christian et al., 1991a). The absolute level of Xwnt-5A transcript declines about10fold during early development, from about $1 \mathrm{pg}$ transcript per cleavage stage embryo to $0.1 \mathrm{pg}$ per embryo by gastrula stage. Levels of Xwnt-5A transcript then increase 20- to 30-

Table 1. Expression and overexpression of Xwnt-5A in Xenopus embryos

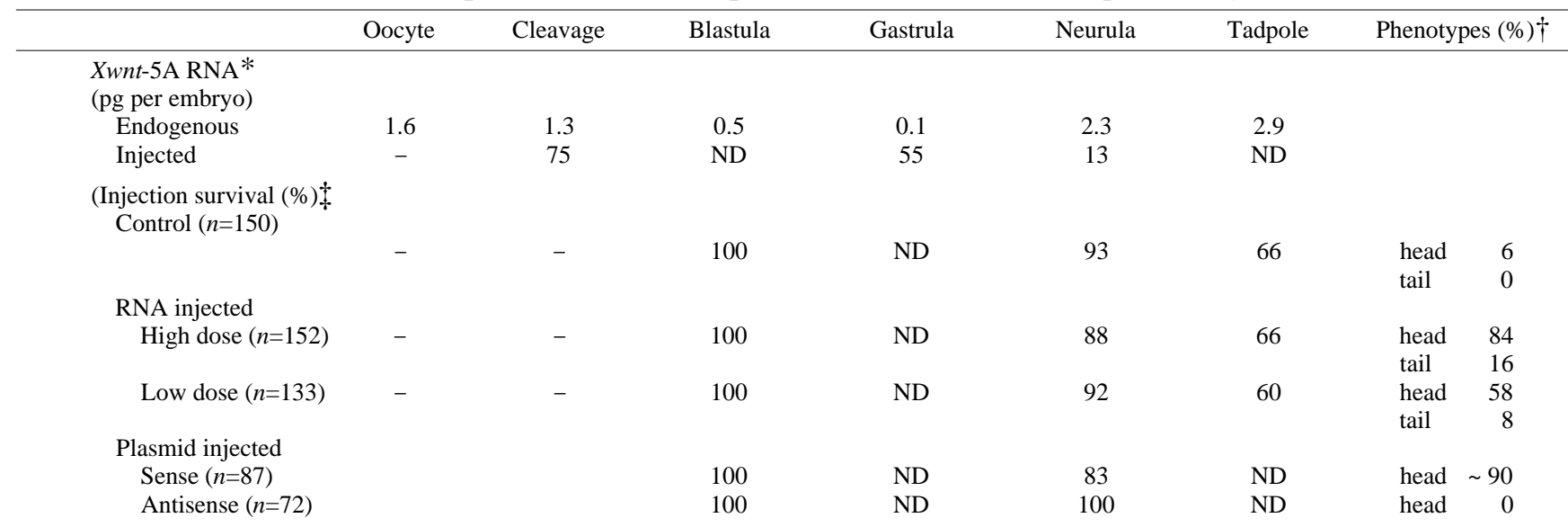

\footnotetext{
*The endogenous levels of Xwnt-5A RNA (in pg) at each developmental stage were estimated by RNase protection assay, using synthetic Xwnt-5A RNA to derive a standard curve. Amounts of synthetic Xwnt-5A injected into eggs, and its persistence in development, was determined in separate experiments by RNA blot analysis. All levels of Xwnt-5A are in pg per embryo. ND, not determined.

\$Eggs were injected with no RNA (control, see also prolactin and inactive Wnt injection controls in text), or with a high dose of Xwnt-5A RNA (approximately $75 \mathrm{pg}$ ), or a low dose of Xwnt-5A RNA (approximately $20 \mathrm{pg} / \mathrm{embryo}$ ). In addition, 4-cell embryos were injected in the dorsal marginal zone with 100-200 pg of plasmid containing Xwnt-5A in the sense or antisense orientation under the control of a cytoskeletal actin promoter. Embryos were cultured to the stages indicated, and $\mathrm{N}$ denotes the number of initial embryos in each culture. Numbers at each developmental stage represent the percentage of initial embryos surviving to this stage. Data for the RNA injections are combined from two similar experiments.

$\dagger$ Percentage of embryos at the tadpole stage with a head or tail defect, with some embryos scored for both defects.
} 


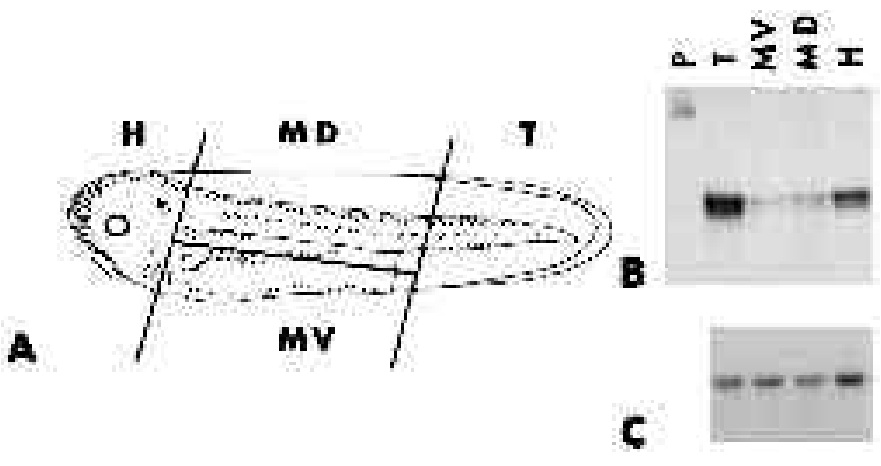

Fig. 2. Localization of Xwnt-5A transcripts in tailbud embryos by RNase protection. (A) Tailbud stage embryos were dissected into head (H), mid-dorsal (MD), mid-ventral (MV) and tail (T) regions as indicated by the solid lines. (B) RNA was isolated from the dissected regions, and subjected to an Xwnt-5A-specific RNase protection assay. The $\mathrm{P}$ lane contains undigested probe, and the remaining lanes, labeled as in A display protected fragments of the predicted size. (C) RNA employed in the RNase protection assay in B was employed in an RNA blot analysis with an EF1 $\alpha$ probe to provide a reference for the relative levels of expression of Xwnt-5A.

fold by neurula and tadpole stages (Table 1). As embryonic transcription commences at mid-blastula transition our analysis of the spatial distribution of Xwnt-5A transcripts (below) is likely based on the localization of newly synthesized transcripts.

We next used the RNase protection assay as an initial approach for asking whether Xwnt-5A was expressed uniformly throughout embryos, or in a spatially restricted manner. Tadpole embryos at approximately stage 40 were chosen for analysis, as Xwnt-5A is more abundant later in development (Christian et al.,1991a; Table 1). Embryos were microdissected into head, tail, mid-dorsal region, and mid-ventral region (Fig. 2A), RNA was isolated, and equivalent amounts of RNA were tested in the RNase protection assay. As shown in Fig. 2B, Xwnt-5A transcripts were detectable in all four regions of the embryo, but were present at higher levels in the head and tail regions compared to the other two regions, upon normalization to an elongation factor $1 \alpha$ probe (Fig. 2C).

The second approach used for investigating the localization of expression of Xwnt-5A employed whole-mount in situ hybridization. As shown in Fig. 3A, hybridization of the antisense probe to late gastrula stage embryos demonstrates that Xwnt-5A transcripts are detectable in a diffuse pattern, enriched in the ectoderm. By the late neurula stage Xwnt-5A transcripts are enriched in the anterior and posterior of the embryo, relative to the middle of the embryo (Fig. 3B,C). This pattern persists in the tadpole, at which stage hybridiz-
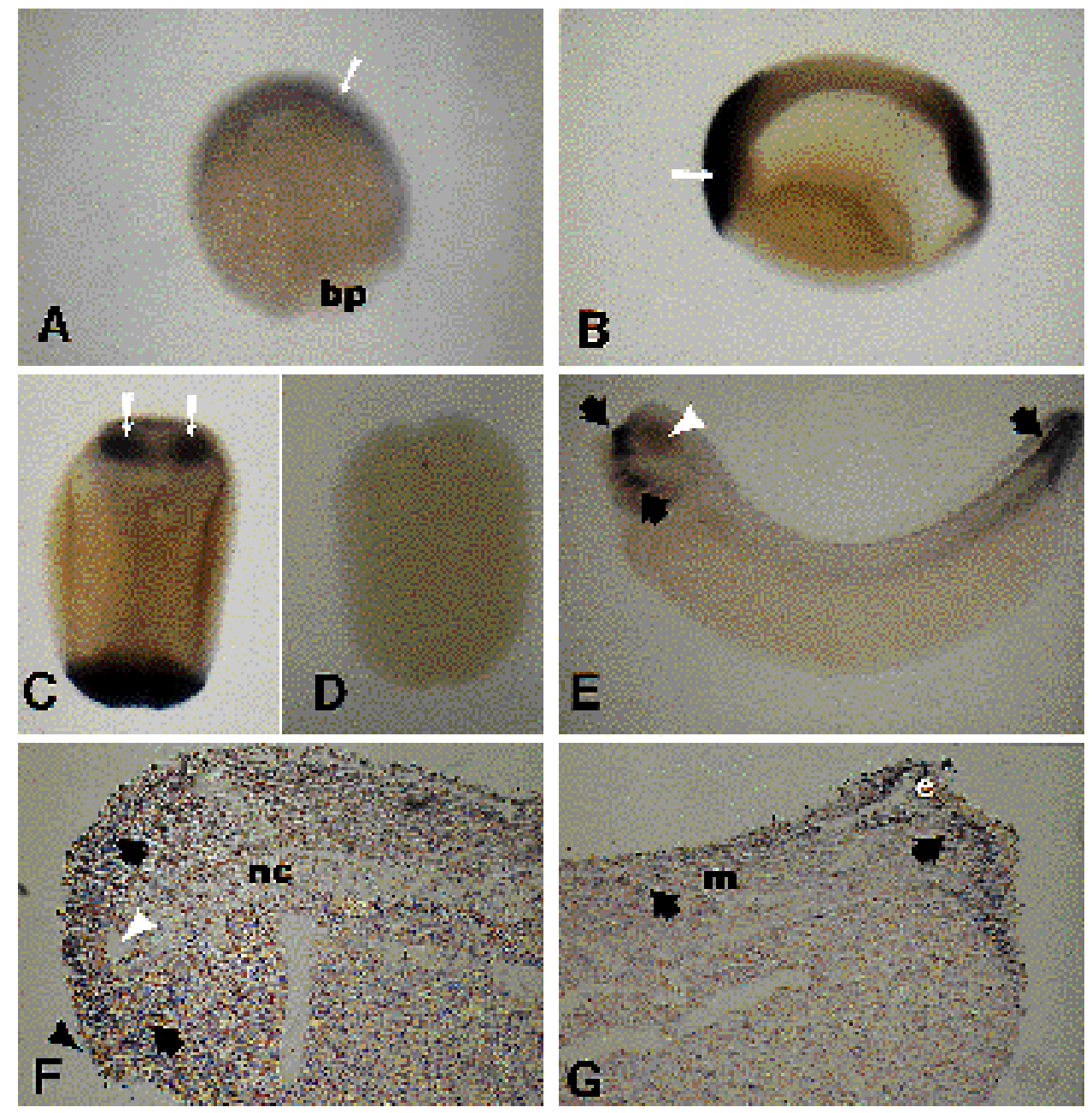

Fig. 3. Localization of Xwnt-5A transcripts by whole-mount in situ hybridization. Developing embryos at (A) the late gastrula (approximately stage 11 1/2); (B, lateral view, $\mathrm{C}$, dorsal view) late neurula (stage 20); and (E) tadpole (stage 34) were hybridized with an antisense Xwnt-5A probe. A dorsal view of control neurula stage embryo hybridized with a sense Xwnt-5A probe is shown in D. Random tadpole embryos were then embedded and sectioned to analyze further the expression of Xwnt-5A in the head (F) and tail (G). White arrows in B and C denote anterior Xwnt-5A hybridization signals. Black arrows $(\mathrm{E}, \mathrm{F}, \mathrm{G})$ denote specific Xwnt-5A hybridization signals. For reference, the eye is denoted by a white arrowhead in $\mathrm{E}$ and $\mathrm{F}$, the cement gland is indicated by a black arrowhead in $\mathrm{F}$, and the blastopore (bp), notochord (nc), tail ectoderm (e), and skeletal muscle $(\mathrm{m})$ are noted. 
ation of the probe is also detected at lower levels in dorsal tissues throughout the embryo (Fig. 3E). This expression of Xwnt-5A throughout tailbud and tadpole embryos, with highest levels at the anterior and posterior ends, is consistent with the above data from the RNase protection assay (Fig. 2).

Following whole-mount in situ hybridization, selected embryos were dehydrated, embedded in paraffin, sectioned, stained with eosin, and examined by bright-field microscopy. At the neurula stage, the ectoderm and mesoderm are the primary tissue layers expressing Xwnt-5A (data not shown). In the head of tadpole stage embryos, $X w n t-5 \mathrm{~A}$ is expressed at highest levels in both neural and non-neural ectoderm (Fig. 3F, large black arrows), with neg- ligible expression in the notochord. As in mouse (Gavin et al., 1990), Xwnt-5A is expressed in facial processes, such as branchial arches (Fig. 3E, lower arrow). Expression of $X w n t-5 \mathrm{~A}$ in mesodermal cells is evident in the trunk and tail, with specific hybridization in somitic mesoderm indicated in Fig. 3G by the left arrow. The expression of Xwnt-5A transcripts in the tail includes both mesodermal and ectodermal cells (Fig. 3G). However, the nature and fate of Xwnt-5A expressing cells is not clearly established.

\section{Effects of overexpression of Xwnt-5A on embryonic development}

Fertilized eggs were injected with Xwnt-5A RNA and the embryos were analyzed for the persistence of the injected
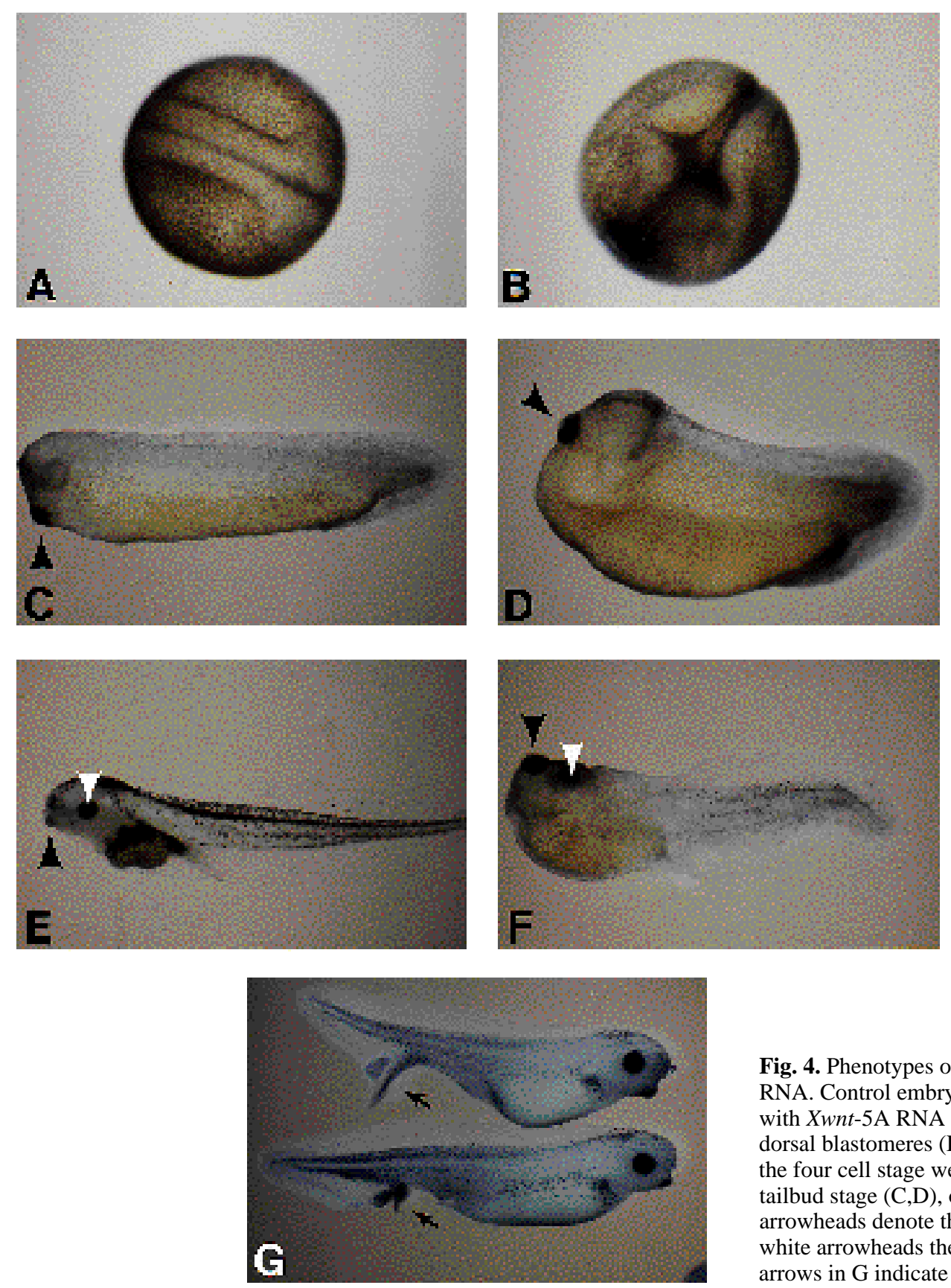

Fig. 4. Phenotypes of embryos injected with Xwnt-5A RNA. Control embryos (A,C,E), and embryos injected with Xwnt-5A RNA into the upper marginal zone of dorsal blastomeres $(\mathrm{B}, \mathrm{D}, \mathrm{F})$ or ventral blastomeres $(\mathrm{G})$ at the four cell stage were cultured to neurula stage (A,B), tailbud stage $(\mathrm{C}, \mathrm{D})$, or tadpole stages $(\mathrm{E}, \mathrm{F}, \mathrm{G})$. Black arrowheads denote the location of the cement gland, and white arrowheads the position of the eye. The black arrows in $\mathrm{G}$ indicate supernumerary tails. 
RNA at selected stages, and for their phenotype. In representative experiments, embryos were injected with approximately $20 \mathrm{pg}$ Xwnt-5A RNA (low dose) or 75 pg RNA (high dose) (Table 1). Approximately 75\% (55 pg) of the high dose persisted to the gastrula stage, and about $17 \%$ (13 pg) persisted to the neurula stage (Table 1).

We next analyzed the phenotypes of embryos injected with Xwnt-5A RNA. Embryos injected with 20-75 pg of Xwnt-5A RNA developed with abnormal phenotypes, which were classified into head and/or tail malformations (Table 1, Fig. 4). In representative experiments, $84 \%$ of injected embryos developed complex head abnormalities, and $16 \%$ of embryos developed supernumerary tails or had other tail defects (Table 1). Shortening of the tail was not scored, though it was apparent to varying degrees in most embryos. A small number of the embryos analyzed in Table 1 had both head and tail malformations. The duplication of the embryonic axis produced by injection of $10 \mathrm{pg}$ of Xwnt-8 RNA (Christian et al., 1991b, 1992) was not observed even after injection of $1 \mathrm{ng}$ of Xwnt-5A RNA (data not shown), suggesting that these Xwnts elicit distinct responses in the embryo. To provide negative controls for injection, we injected up to $1 \mathrm{ng}$ of RNA that encoded either Wnt-1 with a cysteine mutation (McMahon and Moon, 1989), or bovine prolactin (a gift of Peter Walter, UCSF), and did not observe any developmental abnormalities (data not shown).

We next directed the Xwnt-5A RNA to the upper marginal zone of either dorsal or ventral blastomeres at the four cell stage to investigate how this would affect the incidence of the observed phenotypes. In pooled data from three experiments, injection of Xwnt-5A RNA into both dorsal blastomeres produced the head abnormalities described above at higher frequency (95\%, $n=92$ embryos). No duplications of the tail were observed, though the single tail was generally shortened compared to controls. In contrast, injection of Xwnt-5A RNA into both ventral blastomeres at the four cell stage produced primarily wild-type embryos $(80 \%, n=90$ embryos), with a low incidence of embryos with a defective tail $(14 \%)$ and a greatly reduced incidence of embryos with head abnormalities $(6 \%)$.

Embryos injected dorsally with Xwnt-5A RNA often display incomplete closure of the anterior neural tube (Fig. 4B compared to controls, 4A). When control embryos hatch (Fig. 4C), injected embryos display a greatly shortened anterior-posterior axis. At the posterior end, they are nearnormal, though the tails are somewhat shortened. At the anterior end, head structures appear compressed with the cement gland rotated towards the dorsal side (Fig. 4D). Even after control embryos reach the tadpole stages (Fig. 4E), embryos injected dorsally with Xwnt-5A RNA are still considerably shorter (Fig. 4F). Finally, a low percentage of embryos injected at the one cell stage (Table 1), or injected ventrally at the four cell stage, develop with a supernumerary tail (Fig. 4G).

Significantly, dorsal injection of Xwnt-5A plasmid under the control of a cytoskeletal actin promoter, which is not expressed until after midblastula transition (Christian and Moon, 1993b), yields a similar though somewhat less pronounced phenotype as the injected RNA (Table 1). Therefore, the primary developmental abnormalities associated with overexpression of Xwnt-5A, the complex head malformations and shortening of the tail, are likely to result from the activity of $X w n t-5 \mathrm{~A}$ after midblastula transition.

Whole-mount immunocytochemistry with musclespecific and neural-specific monoclonal antibodies was then employed to further our analysis of the phenotypes arising from overexpression of Xwnt-5A. Embryos injected with $X w n t-5 \mathrm{~A}$ RNA in the upper marginal zone of both dorsal blastomeres at the four cell-stage, and cultured to tadpole stages, stained with the pan-neural monoclonal antibody 2G9 (Jones and Woodland, 1989) and revealed an absence of neural tissue anterior to the eyes. Curiously, the anterior neural axis displays a dorsal-ward shift in these embryos (Fig. 5B) when compared with controls (Fig. 5A). In
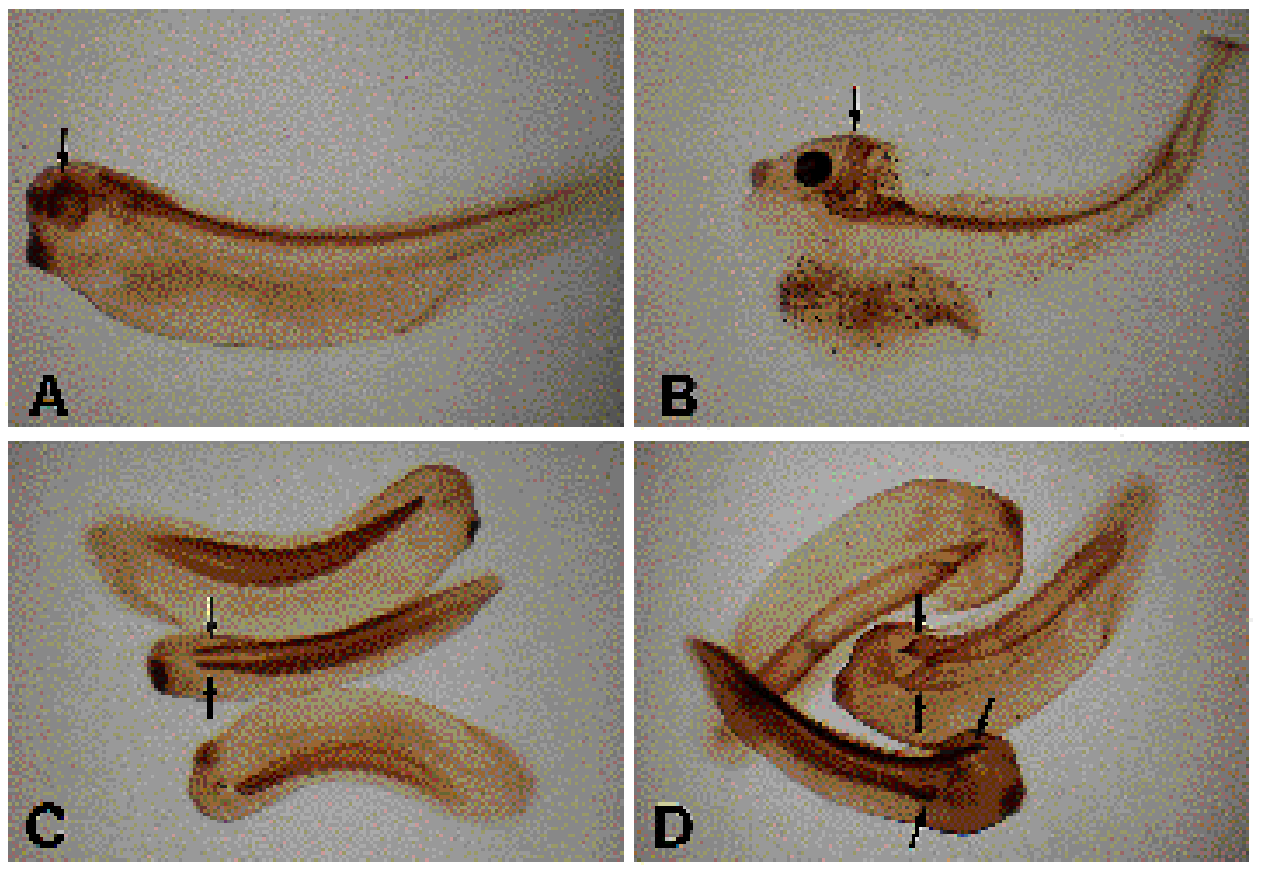

Fig. 5. Whole-mount immunocytochemistry of tailbud and tadpole embryos injected with Xwnt-5A RNA. Control embryos (A,C) and embryos injected with Xwnt-5A RNA in the upper marginal zone of both dorsal blastomeres at the 4-cell stage $(B, D)$ were stained with the pan-neural mAb 2G9 (A,B), or the skeletal muscle-specific $\mathrm{mAb}$ 12/101 (C,D). Arrows in A and B denote the anterior limit of neural staining in dorsally-injected embryos. Arrows in D denote the anterior widening between somitic mesoderm in embryos dorsally injected with Xwnt-5A relative to controls $(\mathrm{C})$. 
addition, eyes often form more medially than in controls. Staining of Xwnt-5A-injected embryos at the tadpole stage with the muscle-specific monoclonal antibody 12/101 (Kintner and Brockes, 1984) revealed a broadening of, and a subtle bifurcation of, dorsal-anterior structures (compare embryos in Fig. 5D with control embryos, in Fig. 5C). The anterior staining pattern with mAb $12 / 101$ is not always symmetrical relative to the dorsal midline of the embryo after injection of Xwnt-5A RNA (Fig. 5D).

\section{Histological analysis of embryos injected with Xwnt-5A RNA}

(1) Pattern anomalies along the anterior-posterior axis Following injection of Xwnt-5A RNA into the upper marginal zone of both dorsal blastomeres at the four cell stage, random embryos were fixed, embedded and sectioned to extend the above analyses of the abnormal phenotype. Significantly, in all embryos examined, head formation was disrupted, though to differing degrees. In addition, although tails appear superficially normal in these embryos (Table 1 , Fig. 4), histological examination generally revealed defects. The first category of developmental defect is the malformation of the axial mesoderm and the overlying nerve cord at specific anteroposterior levels. For example, in the head (Fig. 6D) the nasal placode has fused into a single structure of greater width than that of control embryos (Fig. 6C). In such embryos there is also a corresponding reduction in the size of the telencephalon, along with a dorsal-ward shift of the forebrain (see also Fig. 5B versus control, 5A). This shift placed the nasal placode into the same plane of section as the notochord and somites. Although in this instance the eyes and the diencephalon appear fairly normal (Fig. 6D), in others the diencephalon was much smaller and the eyes fused medially (Fig. 6J versus control Fig. 6I). When the eyes fuse, the telencephalon could not be identified morphologically and the nasal placode does not form (data not shown). Also in those embryos where the eyes fuse, the anterior end of the notochord appears as a bulbous swelling (Fig. 6F), though the somitic mesoderm lateral to the swelling is relatively normal (see also Fig. 5D). Most embryos injected dorsally with Xwnt-5A RNA develop notochords that vacuolate but are malformed at the anterior end (Fig. 6D,F). Posteriorly, most embryos injected dorsally with Xwnt-5A RNA have well defined midbrainhindbrain junctions (data not shown), a near-normal rhombencephalon, and normal otic vesicles (ot, in Fig. 6D,F).

The severity of the abnormalities found in the tail varied widely. In more extreme cases, the tail end of the animal consists of a mass of dissociated cells, comprised of endoderm, mesoderm, and neural ectoderm. This disorgani zation appears gradually, and is preceded by progressively more and more dilated somites (Fig. 6H). In those cases where the tail has formed normally, an unusual positionspecific disruption of the axial tissue array is evident. For example, the embryo in Fig. $6 \mathrm{H}$ exhibits degeneration of three somite segments and an accompanying notochord malformation in those segments. The body ectoderm, overlying neural tube and underlying endoderm at this position in the tail all appear abnormal.
(2) Pattern anomalies along the mediolateral axis A second category of pattern anomalies arising by overexpression of Xwnt-5A is most evident in the trunk region. In approximately $20 \%$ of the embryos there was an evident shift in the position of the neural tube with respect to the notochord (Fig. 6B,G), though there was no apparent local truncation or degeneration of axial tissues. In these embryos, the somitic mesoderm on the side containing the notochord appears fairly normal, while the neural plate is enlarged on the opposite side (e.g., Fig. 6B). In addition, over $90 \%$ of these animals had an intermittent longitudinal groove along the middle of the notochord (Fig. 6D). In longitudinal sections, such grooves appear as 'dark' septa along the length of the notochord. In two out of ten cases, such dark septa were continuous with true bifurcations of the notochord either anteriorly or posteriorly (Fig. 6E).

The pattern abnormalities along both the antero-posterior and medio-lateral axes were observed in multiple experiments, and at both high and low doses of Xwnt-5A RNA. In 10 embryos injected dorsally with plasmid-expressing Xwnt$5 \mathrm{~A}$ in the sense orientation, similar though less pronounced malformations were observed. Embryos injected with antisense orientation Xwnt-5A plasmids developed normally. Thus, the complex phenotypic effects of overexpression of Xwnt-5A likely arise through its action after midblastula transition, as supported by experiments described later.

\section{Determination of blastomere sensitivity to overexpression of Xwnt-5A}

We investigated the sensitivity of different dorsal blastomeres to overexpression of Xwnt-5A. In preliminary experiments, embryos were injected at the 4-cell stage with mixed beta-galactosidase and Xwnt-5A RNAs, cultured to neurula or hatching stages, processed for immunocytochemistry with the anti-beta-galactosidase antibody, embedded in paraffin, and sectioned. In embryos displaying an abnormally formed and/or positioned notochord, the anterior neural structures contained detectable beta-galactosidase, whereas the notochord generally did not (arrow, Fig. 7A). Thus, the shift in neural structures, and the displacement of the notochord, are likely to be the consequences of overexpression of Xwnt-5A in neural ectoderm, rather than a specific effect only on the notochord. As noted above, the head and tail were perturbed to a greater extent than the trunk in embryos overexpressing Xwnt-5A. Thus, in the trunk region of embryos co-injected with beta-galactosidase and Xwnt-5A RNA, we often observed normal neural tubes and/or notochords staining for beta-galactosidase (Fig. 7B).

At the 32-cell stage of development, specific dorsal blastomeres have a high probability of contributing to specific neural or mesodermal structures (Dale and Slack, 1987; Moody, 1987). Therefore, to assess in greater detail which dorsal structures of the 32-cell embryo were most sensitive to overexpression of Xwnt-5A, we mixed Xwnt-5A RNA, at a level sufficient to cause defects when injected dorsally at the four-cell stage, with beta-galactosidase RNA, to confirm which blastomeres were injected, but without implying that beta-galactosidase is a strict lineage marker. The mixture of RNAs was injected into two dorsal midline 
blastomeres of tier one, two, or three of 32-cell embryos, using embryos from the same female. In two representative experiments, the frequency of head abnormalities was $6 \%$ after tier one injection ( $n=64), 74 \%$ after tier two injections $(n=78)$, and $31 \%(n=98)$ after tier three injections (Fig. 7). As expected, based on fate maps of the early embryo (Dale and Slack, 1987; Moody, 1987) beta-galactosidase was detected in tier one-injected embryos (Fig. 7C) primarily in anterior ectoderm, face structures, and anterior brain. The tier two injections (Fig. 7D) labeled the brain to a greater extent relative to the tier one injections, as well as labeling the notochord. Tier three injections
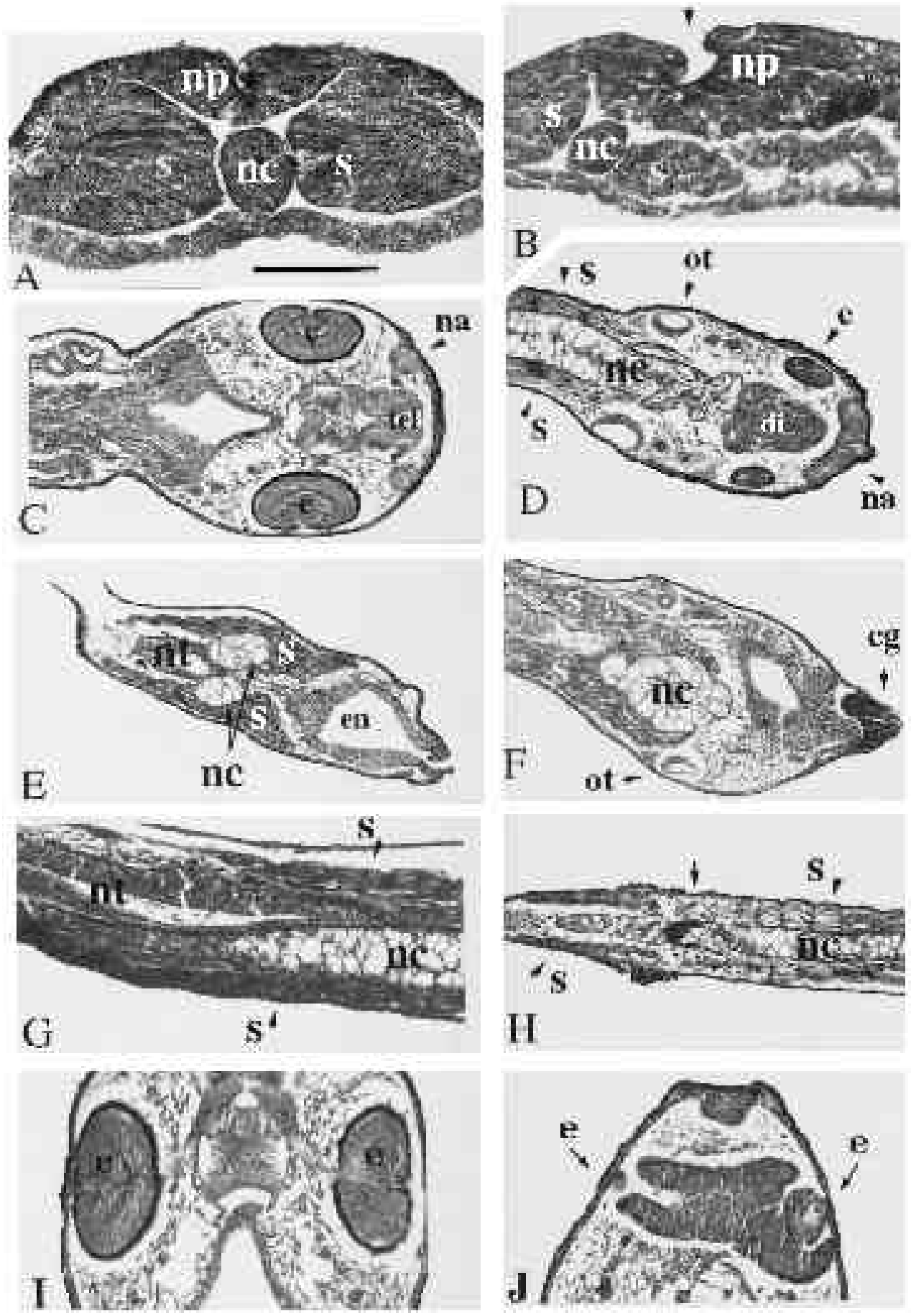

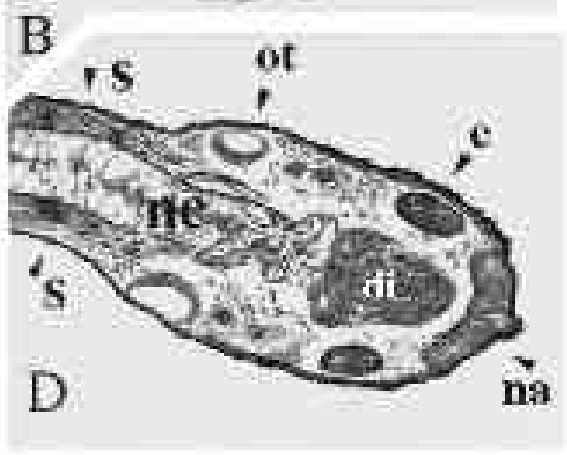

Fig. 6. Histological analysis of embryos injected with Xwnt-5A RNA in the upper marginal zone of both dorsal blastomeres at the 4-cell stage. (A) Control embryo (stage 18-19) sectioned transversely through the trunk region. (B) Xwnt-5A-injected (high dose) embryo (stage 1819) sectioned transversely through the trunk region showing the morphology and positional relationship between the notochord, somites, and neural plate. A pointer marks the position of the dorsal midline with respect to the neural axis. (C) Horizontal section of a control embryo (stage 34-36). (D) Horizontal section through a Xwnt-5Ainjected (high dose) embryo (stage 34-36). This embryo shows a mild phenotype of fused nasal placode, malformed forebrain, and malformed anterior notochord. A subtle bifurcation can also be seen in the notochord, indicated by the dark septum down the middle of the notochord. (E) In some Xwnt-5A-injected embryos the notochord clearly bifurcates, as evident in this cross section through the tail of an embryo at stage 34-36. (F) In most Xwnt$5 \mathrm{~A}$-injected embryos the notochord does not duplicate as in $\mathrm{E}$, rather, it appears as an enlarged bulb anteriorly. (G) This embryo demonstrates that the phenotype observed in B persists at stage 34-36, in horizontal section. $(\mathrm{H})$ This Xwnt-5A-injected embryo demonstrates that occasionally there is a position specific disruption of axial development in the tail. In this stage 34-36 embryo, sectioned horizontally, three somite segments along with the notochord and neural tube in these segments are

seriously disrupted (downward

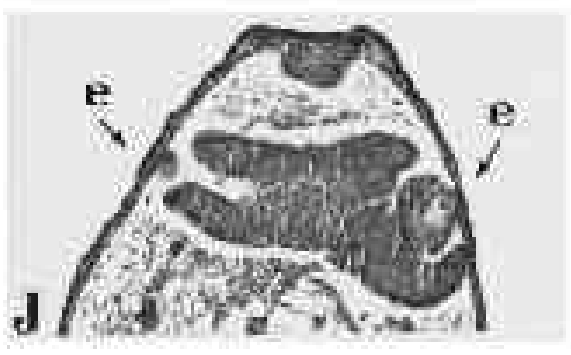

arrow). Axial tissue rostral (upward arrow) and caudal (downward arrowhead) to this disrupted area appear normal. (I) Horizontal section through control embryo at stage 34-36 to denote interocular distance. (J) Horizontal section through Xwnt-5A-injected embryo at stage 34-36 to denote the reduction in interocular distance relative to the sibling control in I. Abbreviations: e, eye; en, endodermal cavity; cg, cement gland; di, diencephalon; np, neural plate; nc, notochord; na, nasal placode; nt, neural tube; ot, otic vesicle; s, somite; tel, telencephalon. The bar in A serves as a reference to the following scales: A and B, $28 \mu \mathrm{m} ; \mathrm{C}-\mathrm{H}, 88 \mu \mathrm{m} ; \mathrm{G}, 105 \mu \mathrm{m}$; and I and J, $65 \mu \mathrm{m}$. 

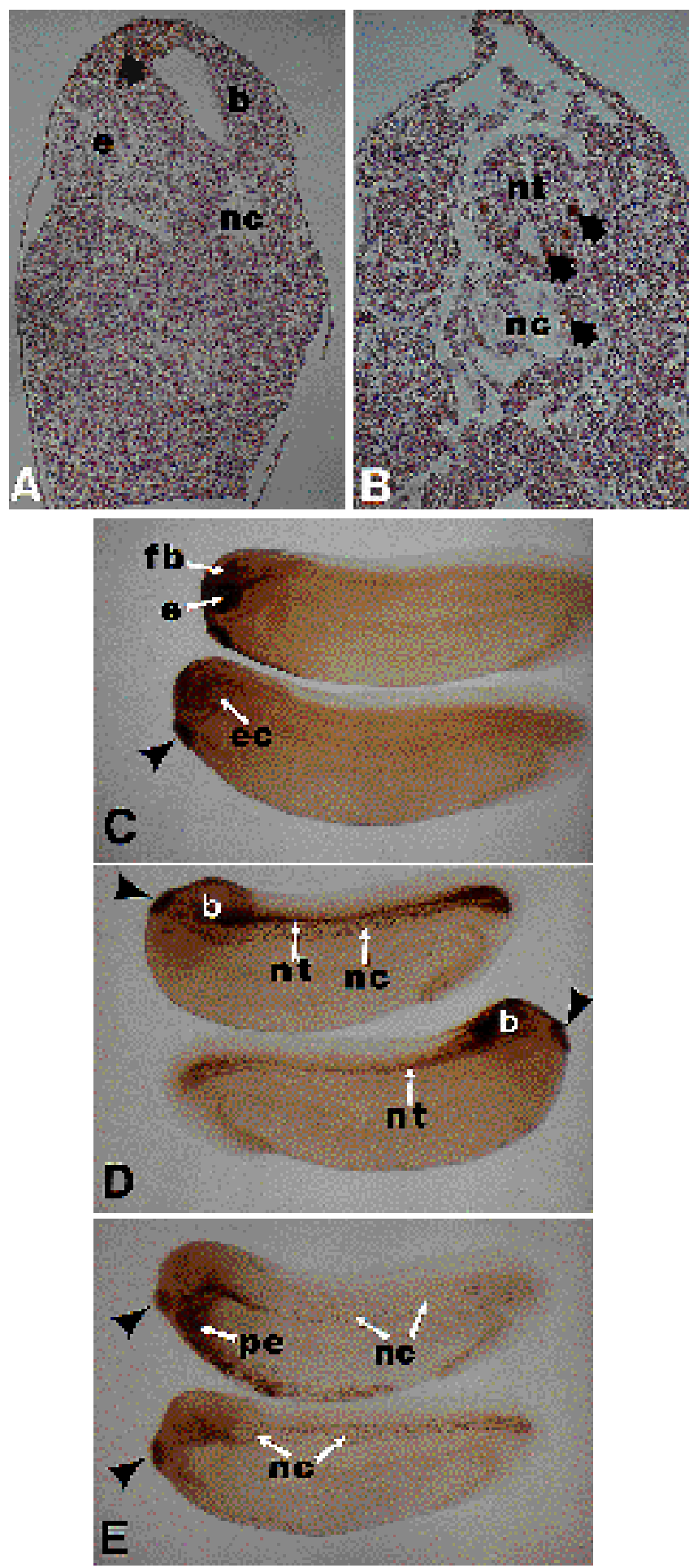

(Fig. 7E) in one of the experiments labeled primarily endoderm in $31 \% \quad(n=15)$ of embryos, endoderm plus mesoderm (either head, notochord, or both) in $31 \%(n=15)$ of embryos, only the notochord in $15 \%(n=7)$ of embryos, and the brain as well as the ectoderm or notochord in $24 \%$ $(n=11)$ of embryos. In 10 of the 11 tier three-injected embryos displaying beta-galactosidase in the brain, head abnormalities of varying degrees were observed, whereas none of the other tier three-injected embryos overtly
Fig. 7. Determination of blastomere sensitivity to overexpression of Xwnt-5A. Mixed Xwnt-5A and beta-galactosidase RNAs were injected into both dorsal blastomeres at the 4-cell stage (A, B), or into two dorsal midline tier one (C), tier two (D), or tier three (E) blastomeres at the 32-cell stage. Hatched embryos were processed for whole-mount immunocytochemical localization of betagalactosidase and photographed $(\mathrm{C}, \mathrm{D}, \mathrm{E})$, or embedded and sectioned through anterior (A) or trunk (B) regions. Arrows denote examples of specific beta-galactosidase staining, and the black arrowheads $(C, D, E)$ denote the position of the cement gland. Abbreviations: b, brain; e, eye; ec, ectoderm; fb, forebrain; nc, notochord; nt, neural tube; pe, pharyngeal endoderm.

displayed head defects. Based on the visual examination (e.g., of representative embryos in Fig. 7), overexpression of Xwnt-5A in dorsal tier two blastomeres, and to a lesser extent tier three blastomeres, produced the highest incidence of the head abnormalities.

\section{Effects of overexpression of Xwnt-5A on the endogenous patterns of expression of goosecoid, Xbra and Xwnt-8}

As ectopic expression of Xwnt-1,-3A, and -8 have the capacity to mimic the Nieuwkoop signalling center (reviewed by Christian and Moon, 1993a), we next investigated whether Xwnt-5A could also mimic this activity, and thereby alter the expression of genes in the marginal zone of the gastrula embryo. Goosecoid is a putative transcription factor expressed in the gastrula organizer (Fig. 8A; Cho et al., 1991), and it is expressed in response to injection of Xwnt-1 RNA in the ventral marginal zone (Christian and Moon, 1993b). Injection of Xwnt-5A RNA into the marginal zone of both dorsal blastomeres of 4-cell embryos did not alter the expression of goosecoid (Fig. 8B), nor did injection into ventral marginal zone (Fig. 8C) promote expression at an ectopic site. We have previously shown that the expression of endogenous Xwnt-8 in the marginal zone (Fig. 8G) is negatively regulated by Nieuwkoop center activity of the blastula, and extends throughout the marginal zone following UV-irradiation (Fig. 8H; Christian and Moon, 1993b). This pattern of expression in UV-irradiated embryos is unaffected by microinjection of Xwnt-5A RNA into the marginal zone of irradiated eggs (Fig. 8I) and, taken with the lack of effect of Xwnt-5A on goosecoid expression, support the conclusion that $X w n t-5 \mathrm{~A}$ lacks the ability to mimic Nieuwkoop center activity. The Xenopus brachyury (Xbra) transcript is expressed in prospective dorsal and ventral mesoderm (Fig. 8D, Smith et al., 1991). Since Xwnt-8 expressed from plasmids promotes formation of ventral mesoderm (Christian and Moon, 1993b), we used expression of Xbra as one indication of whether Xwnt-5A had any affect on the formation of mesoderm. Injection of Xwnt-5A RNA into the marginal zone of both dorsal (Fig. 8E) or ventral (Fig. 8F) blastomeres at the 4-cell stage had no pronounced effect on this pattern.

Interestingly, manual removal of the gastrula stage embryos from their vitelline envelopes prior to fixation for in situ hybridization resulted in the spherical embryos becoming more pear-shaped in Xwnt-5A dorsally injected embryos (Fig. 8B, arrow). Microdissection of unfixed 

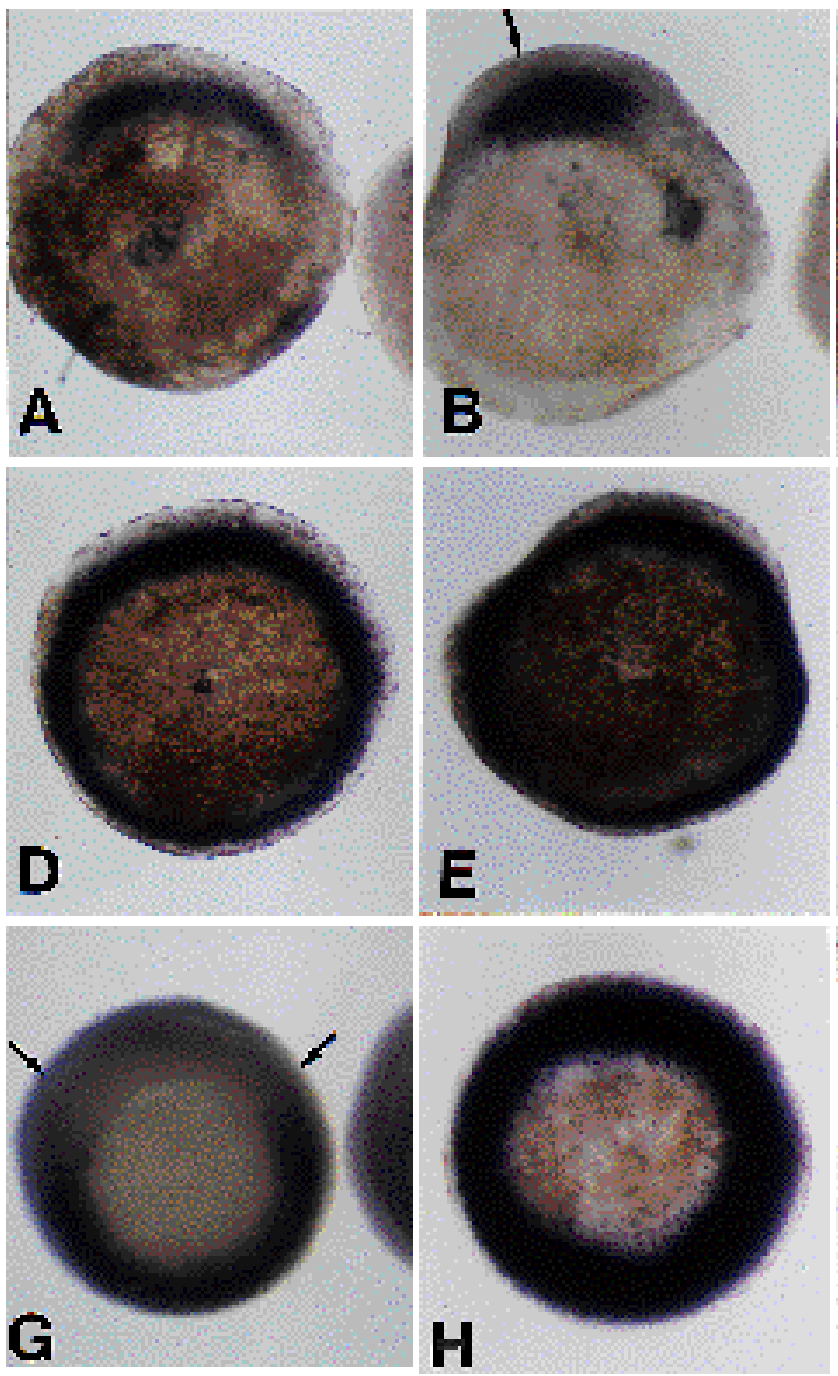
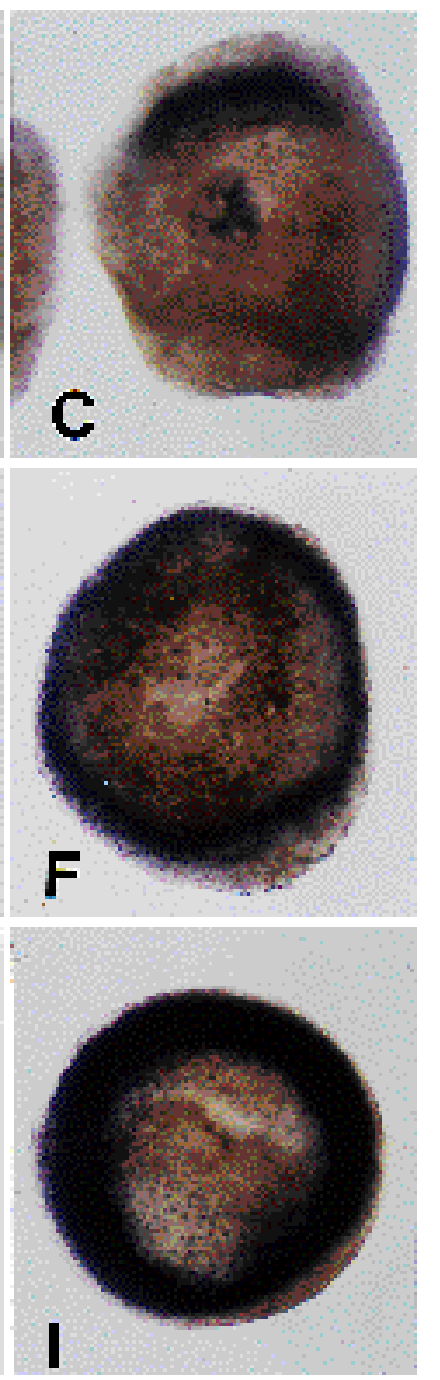

Fig. 8. Effects of overexpression of $X w n t-5 \mathrm{~A}$ on the endogenous patterns of expression of goosecoid, Xbra, and Xwnt-8.

Goosecoid is expressed exclusively in the gastrula organizer of control embryos (A), as well as in embryos injected with $X w n t-5 \mathrm{~A}$ RNA in the marginal zone of both dorsal (B) or ventral (C) blastomeres at the 4-cell stage. Arrow in B denotes slight bulging of the dorsal side. The pattern of expression of endogenous Xbra (D) is similarly unaffected by dorsal (E) or ventral $(\mathrm{F})$ injection of $X w n t-5 \mathrm{~A}$ RNA. $X w n t-8$ is expressed in future ventral and lateral mesoderm of control embryos, and is excluded (between arrows) from the gastrula organizer field (G). UV irradiation of eggs ventralizes the embryo, leading to expression of Xwnt-8 throughout the marginal zone $(\mathrm{H})$, a pattern that is unaffected by injection of $X w n t-5 A$ RNA into the marginal zone (I).

\section{Effects of overexpression of Xwnt-5A on the differentiation of isolated blastula caps}

We then investigated the effect of overexpression of Xwnt$5 \mathrm{~A}$ on the differentiation of blastula cap explants. Xwnt-5A RNA was injected into the animal poles of both blastomeres of 2-cell embryos, and blastula caps were isolated and cultured in vitro until control embryos reached stage 40. Histological examination of these blastula caps (Fig. 9B) revealed that Xwnt-5A led to differentiation of the caps as

Table 2. Effects of overexpression of Xwnt-5A on UVirradiated embryos

diation, and injected doses of Xwnt-5A which were sufficient to generate the head abnormalities in non-irradiated embryos. Embryos were cultured until controls had reached stage 20, then analyzed histologically. As summarized in Table 2, both uninjected UV-irradiated embryos, and Xwnt5A-injected UV-irradiated embryos, developed into ventralized embryos lacking striated muscle, notochords, or neural tubes. Thus, the effects of Xwnt-5A on UV-irradiated embryos are quite distinct from the effects of Xwnt-8 (reviewed by Christian and Moon, 1993a) or Xwnt-9 (Ku and Melton, unpublished data).

\begin{tabular}{lccc}
\multicolumn{4}{c}{ irradiated embryos } \\
\hline & \multicolumn{3}{c}{ Structures detected by histology } \\
\cline { 2 - 4 } & Notochord & Neural tube & Striated muscle \\
\hline Control embryos $(n=20)$ & 95 & 100 & 90 \\
UV embryos $(n=20)$ & 10 & 0 & 5 \\
UV + Xwnt-5A embryos $(n=25)$ & 8 & 0 & 4
\end{tabular}

Uninjected embryos (control), UV-irradiated controls (UV embryos) or UV-irradiated embryos injected with Xwnt-5A RNA (UV+Xwnt-5A) were cultured to stage 20 , fixed, embedded, and sectioned. Numbers represent percentages of embryos displaying the indicated structures, except for $n$, which denotes the sample size. 


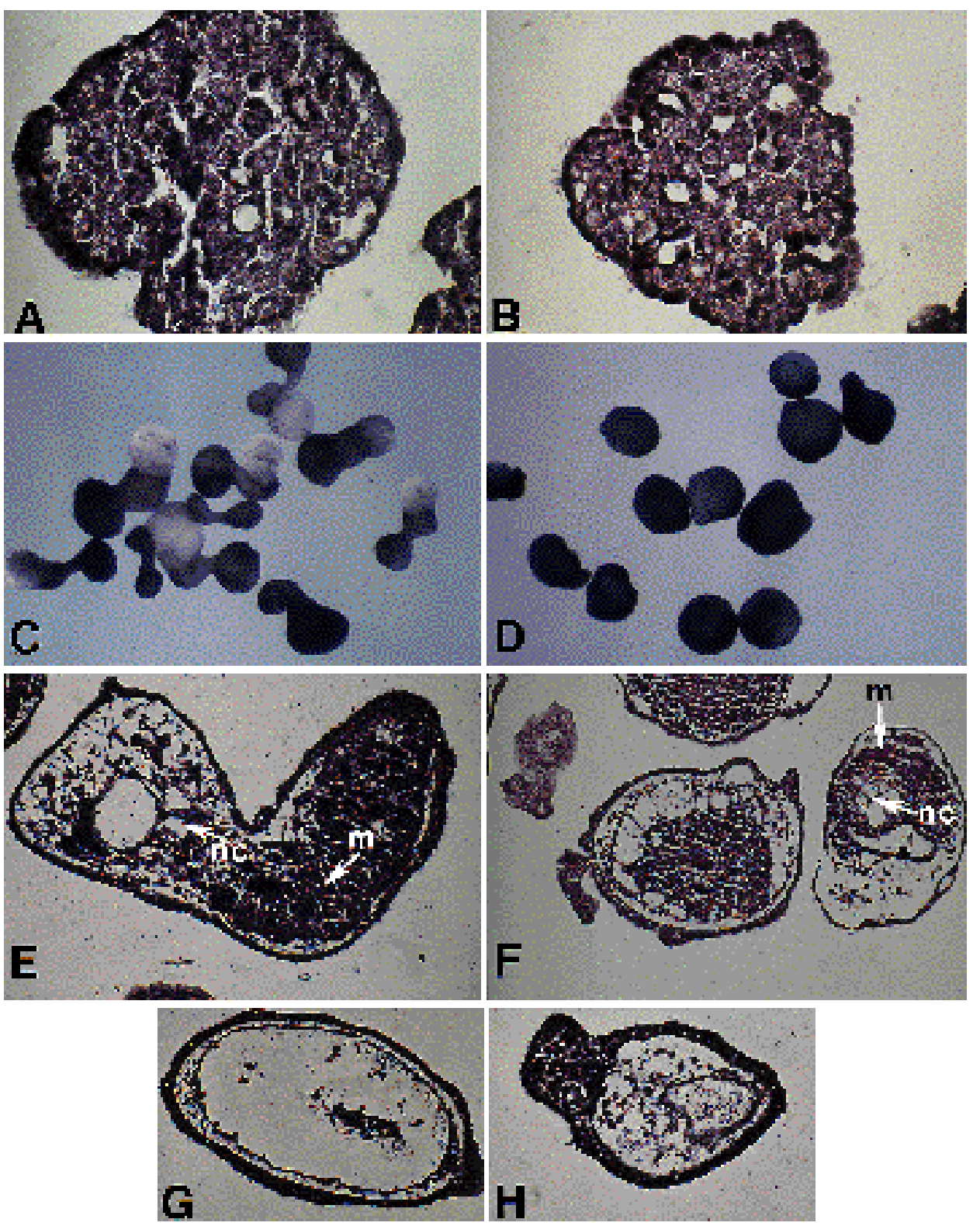

Fig. 9. Effects of overexpression of Xwnt-5A on the differentiation of isolated blastula caps. Histological examination of blastula caps from control embryos (A) and embryos injected with Xwnt-5A RNA in the animal poles of both blastomeres at the 2-cell stage (B) reveals formation of atypical epidermis. Treatment of control explants with recombinant activin A induces extensive elongation of the explants (C), whereas parallel treatment of explants from Xwnt-5A-injected embryos does not induce elongation (D). Histological examination of dorsal halves of control blastula caps (E) reveals skeletal muscle (m) and notochord (nc) in the explants treated with activin A, similar to the mesodermal types in the activin A-treated dorsal halves of caps from Xwnt-5A-injected embryos (F). Ventral halves of blastula caps from control embryos (G) and from Xwnt-5Ainjected embryos $(\mathrm{H})$ treated with activin A display similar ventral mesodermal types (shown here), as well as skeletal muscle (in explants not shown). atypical epidermis, indistinguishable from control blastula caps (Fig. 9A). Therefore, Xwnt-5A is not a mesoderm inducing growth factor in this assay.

Surprisingly, only $10 \%$ of blastula caps from embryos injected with Xwnt-5A RNA elongated when blastula caps were isolated and immediately cultured in $10 \mathrm{ng} / \mathrm{ml}$ recombinant activin A (Fig. 9D), whereas $83 \%$ of blastula caps from control embryos underwent the normal elongation associated with activin-mediated mesoderm induction (Fig. 9C; Table 3). In subsequent experiments, isolated blastula caps were dissected into dorsal or ventral halves, and cultured in the presence or absence of activin A. None of the explants from control embryos elongated in the absence of activin, and treatment of the control explants with activin A resulted in strong elongation in dorsal $(60 \%)$ and ventral (73\%) explants. Consistent with the above analysis of entire blastula caps, few dorsal $(3 \%)$ or ventral $(0 \%)$ blastula caps from embryos injected with Xwnt-5A RNA exhibited elongation in response to activin $\mathrm{A}$. We then examined dorsal and ventral blastula caps histologically to ascertain whether Xwnt-5A affected the mesodermal cell types normally induced by activin A (Table 3). Dorsal explants from both control (Fig. 9E) and Xwnt-5A-injected embryos (Fig. 9F) exhibited notochords in $67 \%$ vs $53 \%$ of explants, respectively, contained skeletal muscle in at least $90 \%$ of explants, and contained ventral mesodermal cell types in $50 \%$ or greater of explants. Activin A-treated ventral explants from both control (Fig. 9G) and Xwnt-5A-injected embryos (Fig. 9H) contained a comparably lower incidence of notochord formation compared to dorsal explants. The ventral explants from both control and Xwnt-5A-injected embryos also contained skeletal muscle and erythroid-like or mesenchymal cells (Table 3) indicative of ventral mesoderm (Green et al., 1990). In summary, overexpression of Xwnt-5A leads to reduced elongation movements in response to activin in isolated blastula caps, without dra- 
Table 3. Effects of overexpression of Xwnt-5A on the differentiation of isolated blastula caps

\begin{tabular}{|c|c|c|c|c|c|c|c|}
\hline & \multirow[b]{2}{*}{$n$} & \multirow[b]{2}{*}{ Elongation at stage 18} & \multirow[b]{2}{*}{$n$} & \multicolumn{4}{|c|}{ Tissues induced at stage 40} \\
\hline & & & & epi & not & $\mathrm{e} / \mathrm{mt}$ & mus \\
\hline \multicolumn{8}{|l|}{ Entire Cap } \\
\hline Control & 16 & 0 & 18 & 89 & 0 & 11 & 0 \\
\hline+ activin & 18 & 83 & & - & - & - & - \\
\hline Xwnt-5A & 8 & 0 & 17 & 94 & 0 & 12 & 0 \\
\hline+ activin & 20 & 10 & & - & - & - & - \\
\hline \multicolumn{8}{|l|}{ Dorsal half } \\
\hline Control & 9 & 0 & 6 & 83 & 0 & 17 & - \\
\hline+ activin & 10 & 60 & 6 & 0 & 67 & 50 & 100 \\
\hline$X w n t-5 \mathrm{~A}+$ activin & 29 & 3 & 19 & 0 & 53 & 100 & 90 \\
\hline \multicolumn{8}{|l|}{ Ventral half } \\
\hline Control & 10 & 0 & 7 & 86 & 0 & 14 & 0 \\
\hline+ activin & 11 & 73 & 8 & 0 & 12 & 88 & 88 \\
\hline$X w n t-5 \mathrm{~A}+$ activin & 26 & 0 & 21 & 0 & 5 & 95 & 43 \\
\hline $\begin{array}{l}\text { The upper one quarter to } \\
\text { dorsal or ventral halves. Ex } \\
\text { elongation, or processed for } \\
\text { epi, atypical epidermis; not }\end{array}$ & of $s$ & $\begin{array}{l}\text { lastula caps were excised } \\
\text { the indicated stage in the } \\
\text { for tissue types. Numbers } \\
\text { troid-like and/or mesothe }\end{array}$ & trol & $\begin{array}{l}\text { cted } \\
\mathrm{ml} \mathrm{r} \\
\mathrm{r} n, \mathrm{r}\end{array}$ & $\begin{array}{l}\text { ind, } \\
\text { th hur } \\
\text { g the }\end{array}$ & $\begin{array}{l}\text { xperin } \\
\text { in A, } \\
\text { size. }\end{array}$ & $\begin{array}{l}\text { ut into } \\
\text { ored fo } \\
\text { ations: }\end{array}$ \\
\hline
\end{tabular}

matically altering the types of mesoderm induced in the explants.

\section{DISCUSSION}

In the present study we have examined the sequence, expression, and consequences of overexpression of a maternal Wnt, Xwnt-5A, which is a member of a family of at least 12 genes in Xenopus (reviewed by Moon, 1993). The intriguing result of this study is that overexpression of Xwnt-5A has no discernible effects upon early development, until the movements of gastrulation commence. The data discussed below are consistent with the possibility that Xwnt-5A has the activity of a modulator of morphogenetic movements, rather than the activity expected of a factor that directly alters cell fate. Cell fate may be affected indirectly by Xwnt-5A, in that morphogenetic movements can affect the positioning or delivery of factors that modulate cell fate.

\section{Expression of Xwnt-5A}

Any understanding of the functions of Xwnt-5A must in part be predicated on an understanding of its spatial patterns of expression. By the neurula stage, Xwnt-5A transcripts are detected primarily in the ectoderm and mesoderm, a pattern that persists into tailbud and tadpole stages. Moreover, by both RNAse protection of RNA from microdissected tailbud embryos, and byin situ hybridization, higher levels of Xwnt$5 \mathrm{~A}$ transcripts are detected in the head and tail, with lower levels in the middle of the embryo. Analysis of thick sections of the embryos processed for whole-mount in situ hybridization demonstrated that Xwnt-5A expression in the head includes both neural and non-neural ectoderm but no expression was noted in the notochord. Similarly, expression of Wnt-5A in mouse embryos is elevated in facial processes (Gavin et al., 1990). While most Xwnts are expressed primarily if not exclusively in neural tissue (reviewed in Moon, 1993), our data indicate that Xwnt-5A is detectable in posterior and somitic mesoderm, as well as in ectoderm.

\section{Effects of overexpression of Xwnt-5A on embryonic development}

To provide insights into which developmental processes are sensitive to levels of Xwnt-5A, we overexpressed Xwnt-5A by injection of synthetic RNA into fertilized eggs. $60-80 \%$ of the injected embryos developed with head defects, while a low percentage of embryos develop normally, or with supernumerary tails. As the frequency of the head defects could be increased to $95 \%$ by directing the RNA to the dorsal blastomeres at the 4-cell stage, we examined these embryos histologically to come to some understanding of the effects of overexpression of Xwnt-5A on Xenopus development. Importantly, at a gross level we find a correlation between the normal pattern of expression of Xwnt-5A, and the regions of the embryos affected by overexpression of Xwnt-5A. That is, head and tail formation were disrupted in all embryos examined histologically. We then asked whether the phenotype arose with equivalent frequency after injection of the top three tiers of blastomeres at the 32-cell stage. We found that the head abnormalities generally correlated with overexpression of Xwnt-5A in neural ectoderm, primarily when the RNA was targeted to tier 2 blastomeres, though this analysis does not directly test the involvement of mesoderm versus neural ectoderm in the abnormal phenotype. Nevertheless, this analysis, in conjunction with other histological and immunocytochemical approaches, suggests that overexpression of Xwnt-5A perturbs the organization of a variety of tissues, without dramatically enhancing or reducing the formation of mesodermal or neuronal structures.

As injected Xwnt-5A RNA was shown to persist above endogenous levels through neurula stage, it is possible that the abnormal phenotypes described above arise by the overexpressed Xwnt-5A acting at any time during the period of overexpression. To address the effects of delaying overexpression of Xwnt-5A until after mid-blastula transition, 
Xwnt-5A was expressed from microinjected plasmids, under the control of a cytoskeletal actin promoter. This resulted in embryos with phenotypes similar to those described above, achieved by targeting RNA to dorsal blastomeres. These data suggest that the developmental abnormalities attributed to overexpression of Xwnt-5A are due to the activity of Xwnt-5A after mid-blastula transition. Whether Xwnt-5A polypeptides are translated from the endogenous maternal Xwnt-5A transcripts, or have any activity prior to midblastula stage, is unknown.

\section{Xwnt-5A does not mimic Nieuwkoop center or gastrula organizer activities}

Several experiments were conducted to test whether Xwnt$5 \mathrm{~A}$ altered mesodermal cell fate, or mimicked Nieuwkoop center or gastrula organizer activities. We found that injection of Xwnt-5A RNA into the marginal zone of either dorsal or ventral blastomeres at the 4-cell stage had no effect on the expression of the gastrula organizer-specific gene, goosecoid. Thus, the activity of Xwnt-5A is distinct from Xwnt-1, which leads to expression of goosecoid following ventral injection of synthetic RNA (Christian and Moon, 1993b). Since goosecoid is expressed in the gastrula organizer in response to signals from the Nieuwkoop center (blastula signalling center) (Christian and Moon, 1993b), these data establish that Xwnt-5A does not mimic the Nieuwkoop center. Similarly, signals downstream of the Nieuwkoop center, probably goosecoid, negatively regulate expression of endogenous Xwnt-8 (Christian and Moon, 1993b). We found that Xwnt-5A RNA has no effect on the endogenous expression of Xwnt8 , further supporting the conclusion that Xwnt-5A cannot mimic Nieuwkoop center activity. If $X w n t-5 \mathrm{~A}$ could mimic the gastrula organizing center, then ventral injection of Xwnt-5A RNA should lead to a secondary dorsal lip during gastrulation, and to a secondary embryonic axis, neither of which is observed.

UV irradiation of fertilized eggs is a useful approach for blocking formation of the Nieuwkoop center and thus gastrula organizer activities, resulting in an embryo with ventral properties (reviewed by Christian and Moon, 1993a). This provides a background into which one can introduce factors to test their ability to rescue dorsal mesodermal, or neural structures. As Xwnt-8 RNA injection into the vegetal hemisphere or marginal zone of UV-irradiated embryos rescues normal development, without injected blastomeres necessarily contributing to dorsal axial structures (Smith and Harland, 1991), Xwnt-8 mimics the Nieukoop center activity (reviewed by Christian and Moon, 1993a). Xwnt-9 partially rescues UV-irradiated embryos to form somitic mesoderm and a spinal cord, but they do not form notochord ( $\mathrm{Ku}$ and Melton, unpublished data). Xwnt-5A is distinct from either of these Xwnts in this assay - it has no ability to rescue formation of a notochord, somitic mesoderm, or a spinal cord.

\section{Xwnt-5A modulates tissue movements but not mesoderm induction}

Blastula caps provide a highly useful cellular environment in which one can test whether the in vitro differentiation of these explants as atypical epidermis can be diverted into pathways leading to other cell types. In the present study, we found that overexpression of Xwnt-5A in blastula cap explants by injection of synthetic RNA did not alter the differentiation of these explants into atypical epidermis, suggesting that Xwnt-5A is not a mesoderm inducing agent. Taken with the inability of Xwnt-5A to alter the expression of mesodermal genes in the marginal zone, and the lack of muscle, notochord, or neural tissue in UV irradiated embryos injected with Xwnt-5A RNA, we conclude that $X w n t-5 \mathrm{~A}$ is not likely to be an inductive agent.

As incubation of blastula caps with mesoderm-inducing growth factors such as basic fibroblast growth factor (bFGF) or activin A leads to formation of dorsal or ventral mesoderm (reviewed in Kimelman et al., 1992), this provides a useful system for asking whether a Xwnt can alter the growth factor responsiveness of the blastula cap. Previously, it was reported that Xwnt-8 RNA enhances the dorsal response of blastula caps to bFGF (Christian et al., 1992) and activin (Sokol and Melton, 1992), such that they undergo greater physical elongation, and express greater levels of muscle actin. Surprisingly, in the present study we found that $X w n t-5 \mathrm{~A}$ has a very distinct effect on the activin responsiveness of blastula cap explants. The explants were blocked in elongation, which has been described as resembling the morphogenetic movements of gastrulation (Symes and Smith, 1987). Interestingly, sectioning the explants revealed that at the one concentration of activin tested, the activin had induced the normal distribution of dorsal and ventral mesodermal cell types. These data, though based on only one concentration of activin, demonstrate that in this context Xwnt-5A has the capacity to alter the morphogenetic movements of tissues, without altering their cell fate. As an aside, these data also indicate that dorsal mesoderm formation can occur in the absence of the morphogenetic movements resulting in the elongation of the blastula caps in response to activin.

Is Xwnt-5A unique in its effect on the activin responsiveness of blastula caps? A dominant inhibitory mutant ras can also block the activin mediated elongation of blastula caps (Whitman and Melton, 1992). However, this effect differs from Xwnt-5A insofar as the mutant ras also blocks mesoderm induction. The effects of Xwnt-5A are also distinct from the effects of bone morphogenetic protein 4 (BMP-4, Dale et al., 1992; Jones et al., 1992). BMP-4 similarly reduces elongation of blastula caps in response to activin but, unlike $X w n t-5 \mathrm{~A}, \mathrm{BMP}-4$ ventralizes the tissue types observed, so that muscle and notochord are rarely formed.

Dorsal and ventral halves of blastula caps have distinct responses to activin (Sokol and Melton, 1991), and expression of Xwnt-8 RNA in the ventral half of blastula caps enhances the competence of the cap to respond to growth factors, so that the ventral half responds like the dorsal half (reviewed by Kimelman et al., 1992; Christian and Moon, 1992). We report that Xwnt-5A does not alter the normally greater responsiveness to activin of dorsal relative to ventral halves of blastula caps, suggesting that Xwnt-5A does not synergize with activin to yield a greater dorsal response to mesoderm induction, and suggesting that Xwnt$5 \mathrm{~A}$ is not normally involved in the competence of tissue to respond to mesoderm inducing growth factors. 


\section{Ectopic expression of Xwnts suggest multiple Wnt signalling pathways}

Although over a dozen Wnts have been identified, there have been few data addressing whether Wnts in any species are functionally redundant, or activate distinct pathways. Several experiments in Xenopus bear on this issue. First, injection of RNA encoding Xwnt-8 (Sokol et al., 1991; Smith and Harland, 1991), Xwnt-5A (present study), and Xwnt-9 (Ku and Melton, unpublished data) into UV-irradiated embryos produce three distinct phenotypes. Second, $X w n t-5 \mathrm{~A}$ and -8 have distinct effects on modulating gap junctional permeability in early embryos (Olson et al., 1991), and on the growth factor responsiveness of blastula caps. Third, Xwnt-5A is distinct from Wnt-1 in its inability to transform C57 mammary epithelial cells (Olson et al., unpublished). Fourth, Xenopus blastomeres differ in their sensitivity to overexpression of Xwnts - dorsal blastomeres are sensitive to injection of Xwnt-5A RNA but not Xwnt-8 RNA, whereas the converse is true for ventral blastomeres. Thus, it is likely that there are multiple signal transduction pathways activated by Xwnts. Alternatively, a single pathway may be activated by all Xwnts, but the amplitude or duration of activation differ in response to distinct Xwnts. Indicating that some Xwnts can activate the same pathways, the Xwnt-8 response is likely to be indistinguishable from the effects of Xwnts-1 and -3A (Wolda et al., 1993; reviewed by Moon, 1993).

\section{Speculation on the functions of Xwnt-5A}

We speculate that $X w n t-5 \mathrm{~A}$ activates a receptor-mediated signal transduction pathway, which ultimately leads to changes in cell adhesion, and to changes in the morphogenetic movements of tissues. Three lines of evidence support this hypothesis. First, from assays monitoring gap junctional permeability at the 32-cell stage, observing phenotype, and investigating the expression of mesodermal markers at the gastrula stage, overexpression of Xwnt-5A has no effect upon the embryo until the morphogenetic movements of gastrulation commence. Importantly, Xwnt$5 \mathrm{~A}$ does affect the movements of gastrulation in Keller explants (Shih et al., unpublished data), consistent with the phenotype of the intact embryo overexpressing Xwnt-5A, reported here. Second, Xwnt-5A blocks the elongation of blastula caps in response to activin, without altering the types of mesoderm formed within the explants. Third, preliminary evidence suggests that $X w n t-5 \mathrm{~A}$ reduces the normal mixing of ectodermal cells during gastrulation (Moon et al., unpublished data), much as Detrick et al. (1990) found in response to overexpression of $\mathrm{N}$-cadherin.

There is accumulating evidence that Wnts may act at a cellular level to alter cell adhesion (reviewed by Moon et al., 1993). In part, this is based on data establishing that the armadillo gene, involved in the Wnt-1 signalling pathway in Drosophila, is homologous to vertebrate plakoglobin and to the E-cadherin-associated protein, beta-catenin. As Xenopus embryos express both beta-catenin and plakoglobin (DeMarais and Moon, 1992), and as Xwnt-5A has effects upon cell movements, there are new opportunities for investigation of how Wnt signalling may affect cell adhesion.

We thank D. Melton and M. Ku for communication of unpub- lished Xwnt-9 data and for the oocyte cDNA library, P. Moore and Genentech for the recombinant human activin A, P. Walter for the prolactin cDNA, R. Perlmutter for the elongation factor cDNA, J. Smith for the Xbra cDNA, C. Kintner for the 12/101 antibody, R. Harland for the beta-galactosidase cDNA and E. Jones and $\mathrm{H}$. Woodland for the 2G9 antibody. We thank A. DeMarais and G. Kelly for helpful comments on the manuscript and for technical assistance, and J. Papkoff and D. Olson for transfecting Xwnt-5A into C57mg cells. This work was supported by Public Health Service Awards (RO1 HD27525, HD29360, and KO4 AR 1837 to R. T. M.) and fellowship HD07528 to L. L. M.

\section{REFERENCES}

Ausubel, F. M., Brent, R., Kingston, R. E., Moore, D. D., Seidman, J. G., Smith, J. S. and Struhl, K. (1988). Current protocols in molecular biology. New York: John Wiley and Sons.

Bradley, R. S. and Brown, A. M. C. (1990). The proto-oncogene int-1 encodes a secreted protein associated with the extracellular matrix. EMBO J. 9, 1569-1575.

Christian, J. L., Gavin, B. J., McMahon, A. P. and Moon, R. T. (1991a). Isolation of cDNAs partially encoding four Xenopus Wnt-1/int-1-related proteins and characterization of their transient expression during embryonic development. Dev. Biol. 143, 230-234.

Christian, J. L., McMahon, J. A., McMahon, A. P. and Moon, R. T. (1991b). Xwnt-8, a Xenopus Wnt-1/int-1-related gene responsive to mesoderm-inducing growth factors, may play a role in ventral mesodermal patterning during embryogenesis. Development 111, 10451055.

Christian, J. L., Olson, D. J. and Moon, R. T. (1992). Xwnt-8 modifies the character of mesoderm induced by bFGF in isolated Xenopus ectoderm. EMBO J. 11, 33-41.

Christian, J. L. and Moon, R. T. (1993a). When cells take fate into their own hands: Differential competence to respond to inducing signals generates diversity in the embryonic mesoderm. BioEssays 15, 135-140.

Christian, J. L. and Moon, R. T. (1993b). Interactions between Xwnt-8 and Spemann organizer signaling pathways generate dorsoventral pattern in the embryonic mesoderm of Xenopus. Genes Dev. 7, 13-28.

Cho, K. W. Y., Blumberg, B., Steinbesser, H. and DeRobertis, E. M. (1991). The molecular nature of Spemann's organizer: the role of the Xenopus homeobox gene goosecoid. Cell 67, 1111-1120.

Dale, L. and Slack, J. M. W. (1987). Fate map for the 32-cell stage of Xenopus laevis. Development 99, 527-551.

Dale, L., Howes, G., Price, B. M. J. and Smith, J. C. (1992). Bone morphogenetic protein 4: a ventralizing factor in early Xenopus development. Development 115, 573-585.

DeMarais, A. A. and Moon, R. T. (1992). The armadillo homologs $\beta$ catenin and plakoglobin are differentially expressed during early development of Xenopus laevis. Dev. Biol. 153, 337-346.

Detrick, R. J., Dickey, D. and Kintner, C. R. (1990). The effects of Ncadherin misexpression on morphogenesis in Xenopus embryos. Neuron 4, 493-506.

Feinberg, A. and Vogelstein, B. (1984). A technique for radiolabelling DNA restriction endonuclease fragments to high specific activity. Analyt. Biochem. 137, 266-267.

Gavin, B. J., McMahon, J. A. and McMahon, A. P. (1990). Expression of multiple novel Wnt-1/int-1-related genes during fetal and adult mouse development. Genes Dev. 4, 2319-2332.

Green, J. B. A., Howes, G., Symes, K., Cooke, J. and Smith, J. C. (1990). The biological effects of XTC-MIF: Quantiative comparison with Xenopus bFGF. Development 108, 173-183.

Gurdon, J. B. and Wickens, M. P. (1983). The use of Xenopus oocytes for the expression of cloned genes. Methods Enzymol. 101, 370-386.

Harland, R. M. (1991). In situ hybridization: An improved whole-mount method for Xenopus embryos. MethodsCell Biol. 36, 685-695.

Jones, C. M., Lyons, K. M., Lapan, P. M., Wright, C. V. E. and Hogan, B. L. M. (1992). BVR-4 (Bone morphogenetic protein-4) as a posteriorventralizing factor in Xenopus mesoderm induction. Development 115, 639-647. 
Jones, E. A. and Woodland, H. R. (1989). Spatial aspects of neural induction in Xenopus laevis. Development 107, 785-791.

Jue, S. F., Bradley, R. S., Rudnicki, J. A., Varmus, H. E. and Brown, A. M. C. (1992). The mouse Wnt-1 gene can act via a paracrine mechanism in transformation of mammary epithelial cells. Molec. Cell Biol. 12, 321328.

Kelly, G. M., Eib, D. W. and Moon, R. T. (1991). Histological preparation of Xenopus laevis oocytes and embryos. Methods Cell Biol. 36, 389417.

Kimelman, D., Christian, J. L. and Moon, R. T. (1992). Synergistic principles of development: Overlapping patterning systems in Xenopus mesoderm induction. Development 116, 1-9.

Kintner, C. and Brockes, J. P. (1984). Monoclonal antibodies to the cells of a regenerating limb.J. Embryol. Exp. Morph. 89, 37-55.

Klymkowsky, M. W. and Hanken, J. (1991). Whole mount staining of Xenopus and other vertebrates. Methods Cell Biol. 36, 420-441.

Krauss, S. Korzh, V., Fjose, A. and Johansen, T. (1992). Expression of four zebrafish wnt-related genes during embryogenesis. Development 116, $249-259$

Krieg, P. A. and Melton, D. A. (1984). Functional messenger RNAs are produced by SP6in vitro transcription of cloned cDNAs. Nucl. Acids Res. 12, 7057-7070.

Maniatis, T., Fritsch, E. F. and Sambrook, J. (1982). Molecular Cloning. A Laboratory Manual. New York: Cold Spring Harbor Laboratory.

McMahon, A. P. (1992). A super family of putative developmental signaling molecules related to the proto-oncogene Wnt-1/int-1. Adv. Dev. Biol. 1, 31-60.

McMahon, A. P. and Moon, R. T. (1989). Ectopic expression of the protooncogene int -1 in Xenopus embryos leads to duplication of the embryonic axis. Cell 58, 1075-1084.

McMahon, A. P. and Bradley, A. (1990). The Wnt-1 (int-1) protooncogene is required for development of a large region of the mouse brain. Cell 62, 1073-1085.

Moody, S. A. (1987). Fates of the blastomeres of the 32-cell-stage Xenopus embryo. Dev. Biol. 122, 300-319.

Moon, R. T. and Christian, J. L. (1989). Microinjection and expression of synthetic mRNAs in Xenopus embryos. Technique 1, 76-89.

Moon, R. T. and Christian, J. L. (1992). Competence modifiers synergize with growth factors during mesoderm induction and patterning in Xenopus. Cell 71, 708-712.

Moon, R. T. (1993). In pursuit of the functions of the Wnt family of developmental regulators: Insights from Xenopus laevis. BioEssays 15, 91-97.

Moon, R. T., DeMarais, A. A. and Olson, D. J. (1993). Responses to Wnt signals in vertebrate embryos may involve changes in cell adhesion and cell movement. J. Cell. Sci. Supplement(in press)

Noordermeer, J., Meijlink, F., Verrijzer, P., Rijsewijk, F. and Destree, O. (1989). Isolation of the Xenopus homolog of int-1/wingless and expression during neurula stages of early development. Nucl. Acids Res. 17, 11-18

Nusse, R. and Varmus, H. E. (1992). Wht genes. Cell 69, 1073-1087.

Olson, D. J., Christian, J. L. and Moon, R. T. (1991). Effect of Wnt-1 and related proteins on gap junctional communication in Xenopus embryos. Science 252, 1173-1176.

Papkoff, J. and Schryver, B. (1990). Secreted int-1 protein is associated with the cell surface. Mol. Cell Biol. 10, 2723-2730.

Rebagliati, M. R., Weeks, D. L., Harvey, R. P. and Melton, D. A. (1985). Identification and cloning of localized maternal RNAs from Xenopus eggs. Cell 42, 769-777.

Rijsewijk, F., Schuermann, M., Wagenaar, E., Parren, P., Weigel, D. and Nusse, R. (1987). The Drosophila homolog of the mouse mammary oncogene int-1 is identical to the segment polarity gene wingless. Cell $\mathbf{5 0}$, 649-657.

Sanger, F., Nicklen, S. and Coulson, A. R. (1977). DNA sequencing with chain-terminating inhibitors. Proc. Natl. Acad. Sci. USA 74, 5463-5467.

Sive, H. L. (1993). The frog prince-ss: A molecular formula for dorsoventral patterning in Xenopus. Genes Dev. 7, 1-12.

Smith, J. C., Price, B. M. J., Green, J. B. A., Weigel, D. and Herrmann, B. G. (1991). Expression of a Xenopus homolog of Brachyury (T) is an immediate-early response to mesoderm induction. Cell 67, 79-87.

Smith, W. C. and Harland, R. M. (1991). Injected Xwnt-8 RNA acts early in Xenopus embryos to promote formation of a vegetal dorsalizing center. Cell 67, 753-765.

Sokol, S., Christian, J. L., Moon, R. T. and Melton, D. A. (1991). Injected Wnt RNA induces a complete body axis in Xenopus embryos. Cell 67, 741-752.

Sokol, S. and Melton, D. A. (1991). Pre-existent pattern in Xenopus animal pole cells revealed by induction with activin. Nature 351, 409-411.

Sokol, S. Y. and Melton, D. A. (1992). Interaction of Wnt and activin in dorsal mesoderm induction in Xenopus. Dev. Biol. 154, 1-8.

Symes, K. and Smith, J. C. (1987). Gastrulation movements provide an early marker of mesoderm induction in Xenopus laevis. Development 101, 339-349.

Thomas, K. R. and Capecchi, M. R. (1990). Targeted disruption of the murine int-1 proto-oncogene resulting in severe abnormalities in midbrain and cerebellar development. Nature 346, 847-850.

van den Heuvel, M., Nusse, R., Johnston, P. and Lawrence, P. A. (1989). Distribution of the wingless gene product in Drosophila embryos: A protein involved in cell-cell communication. Cell 59, 739-749.

Whitman, M. and Melton, D. A. (1992). Involvement of p21 ras in Xenopus mesoderm induction. Nature 357, 252-254.

Wolda, S. L., Moody, C. J. and Moon, R. T. (1993). Overlapping expression of Xwnt-3A and Xwnt-1 in neural tissue of Xenopus laevis embryos. Dev. Biol. 155, 46-57.

(Accepted 27 May 1993) 